\title{
Durability of E-glass fiber reinforced vinyl ester polymer composites with nanoclay in an alkaline environment
}

Naveenkamal Ravindran

West Virginia University

Follow this and additional works at: https://researchrepository.wvu.edu/etd

\section{Recommended Citation}

Ravindran, Naveenkamal, "Durability of E-glass fiber reinforced vinyl ester polymer composites with nanoclay in an alkaline environment" (2005). Graduate Theses, Dissertations, and Problem Reports. 1640. https://researchrepository.wvu.edu/etd/1640

This Thesis is protected by copyright and/or related rights. It has been brought to you by the The Research Repository @ WVU with permission from the rights-holder(s). You are free to use this Thesis in any way that is permitted by the copyright and related rights legislation that applies to your use. For other uses you must obtain permission from the rights-holder(s) directly, unless additional rights are indicated by a Creative Commons license in the record and/ or on the work itself. This Thesis has been accepted for inclusion in WVU Graduate Theses, Dissertations, and Problem Reports collection by an authorized administrator of The Research Repository @ WVU. For more information, please contact researchrepository@mail.wvu.edu. 


\title{
Durability of E-Glass Fiber Reinforced Vinyl Ester Polymer Composites with Nanoclay in an Alkaline Environment
}

\author{
Naveenkamal Ravindran \\ Thesis submitted to the \\ College of Engineering and Mineral Resources \\ at West Virginia University \\ in partial fulfillment of the requirements for the degree of \\ Master of Science \\ In \\ Chemical Engineering \\ Department of Chemical Engineering \\ Dr. Eung H. Cho, Committee Chairperson, ChE \\ Dr. Hota V. Gangarao, Committee Member, CEE \\ Dr. Rakesh K. Gupta, Committee Member, ChE
}

West Virginia University, WV

2005

Keywords: Vinyl ester, Glass fiber, Nanoclay, Nanocomposites, GFRP, Alkaline solution, Sustained load, Diffusion studies 


\section{ABSTRACT \\ Durability of E-Glass Fiber Reinforced Vinyl Ester Polymer Composites with \\ Nanoclay in an Alkaline Environment}

Naveenkamal Ravindran

This study was conducted to determine the effect of clay content in the GFRP (glass fiber reinforced polymer) composite samples as they are aged in an alkaline solution. Two kinds of GFRP composite samples were prepared. One was E-glass fiber reinforced vinyl ester polymer and the other was nano-GFRP prepared with the addition of 1 and $2 \mathrm{wt} \%$ of montmorillonite clay. These samples were aged in alkaline solution of $\mathrm{pH} 13.2$ with and without sustained load. The load was $1335 \mathrm{~N}$ or $18.75 \%$ of the tensile strength of the composite samples. The aging was evaluated by measuring the reduction in tensile strength after 6 months. Also, absorption of alkaline solution into the plain and nano-GFRP samples was investigated in order to elucidate the diffusion behaviors.

It has been found that for a short exposure time (e.g. one month) and without sustained load, dispersing $2 \mathrm{wt} \%$ of the nanoclay in the polymer matrix of the GFRP samples reduces the diffusivity by $39 \%$. However, with the application of sustained load, the glass fiber composite samples deteriorate more with increasing clay content. The reduction in tensile strength is $7.5 \%, 12.4 \%$ and $18 \%$ for the samples containing 0,1 and $2 \mathrm{wt} \%$ clay, respectively. 


\section{ACKNOWLEDGEMENTS}

I would like to thank Dr. Dady Dadyburjor for providing me an opportunity to pursue my M.S in the Department of Chemical Engineering, WVU.

My heartfelt gratitude to Dr. Eung Cho, my research advisor, who has been a wonderful guide through these last two years. I would like to acknowledge the invaluable inputs given by my committee members, Dr. Rakesh Gupta and Dr. Hota Gangarao during various stages of my research. I would like to thank Dr. Ray Liang and Dr. P.V. Vijay for their suggestions and ideas.

I would like to acknowledge Mr. Jim Hall for always helping me in setting up my experiments in time. My deepest gratitude to the U.S. Department of Transportation for funding this project. I would also like to thank Mr. Ken Tibbeppes of East Tech Company and Mr. Trevor Humphrey of Vectorply Corp., for supplying us with the vinyl ester resin and the glass fiber.

My heartfelt thanks to my parents and my sister for their constant love and all the phone calls. A big thank you to my friends, Rajesh, Vani, Balaji, Amar and all my classmates for making my stay in WVU all the more enjoyable. 


\section{TABLE OF CONTENTS}

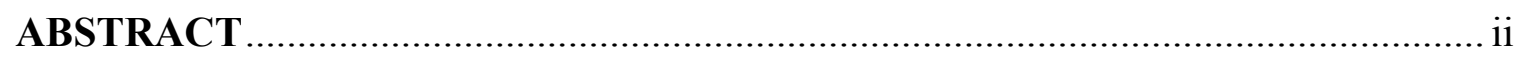

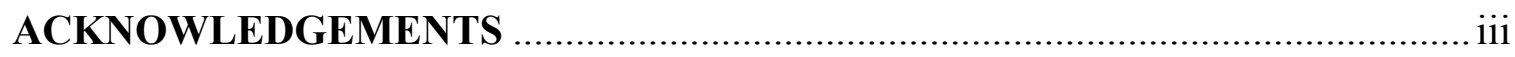

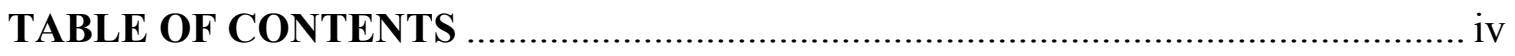

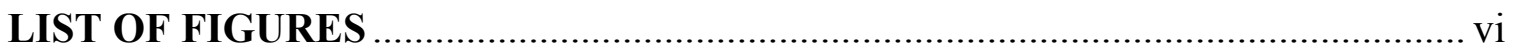

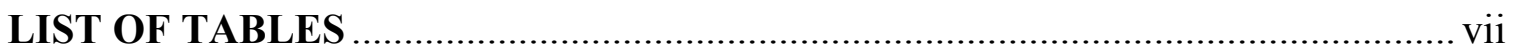

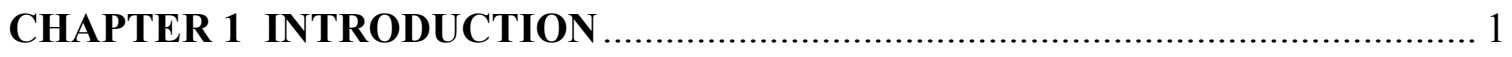

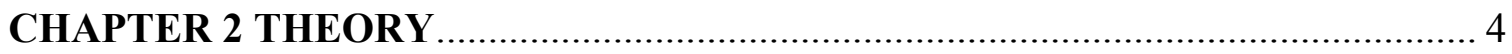

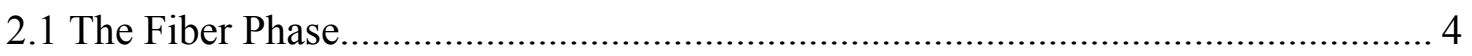

2.2 The Resin Phase .............................................................................................. 5

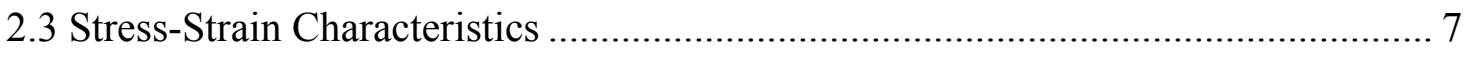

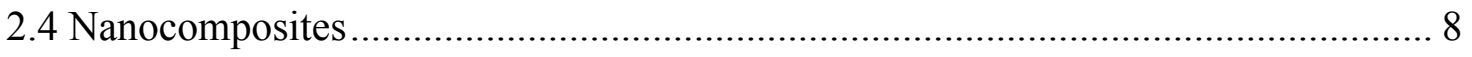

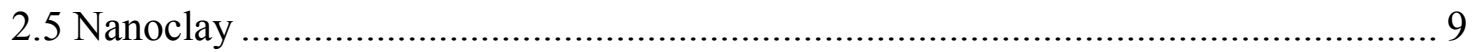

2.6 Diffusion in Nanocomposites ..................................................................... 9

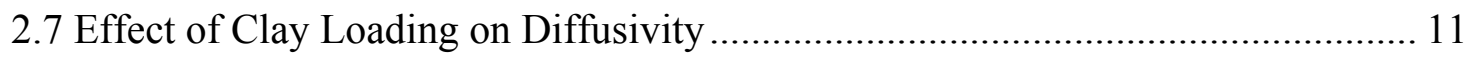

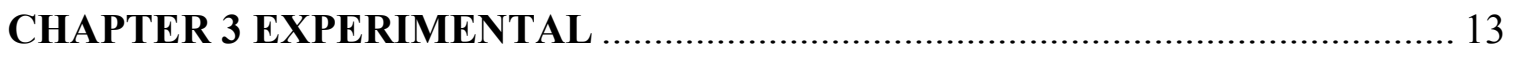

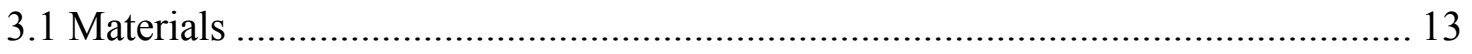

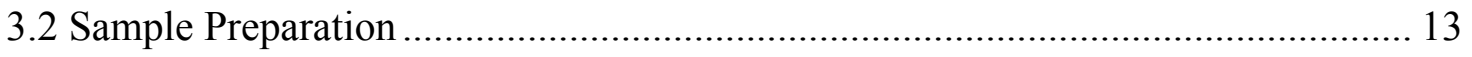

3.3 Characterization Tests.............................................................................. 14

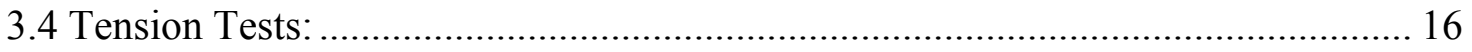

3.5 Alkaline Sorption Tests............................................................................ 16

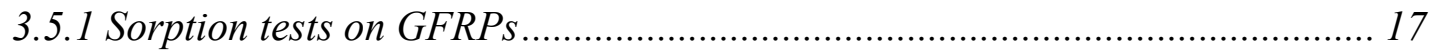




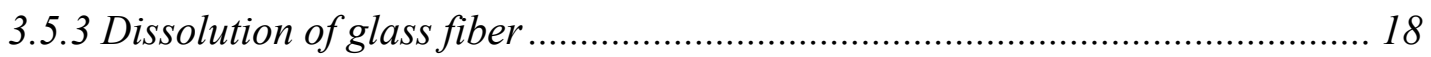

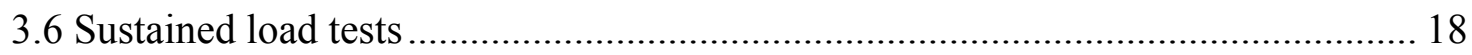

3.7 Reduction in Tensile strength of aged GFRPs ................................................ 19

CHAPTER 4 RESULTS AND DISCUSSION .................................................. 20

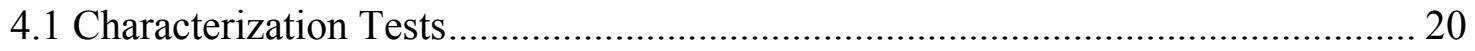

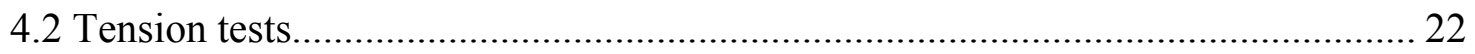

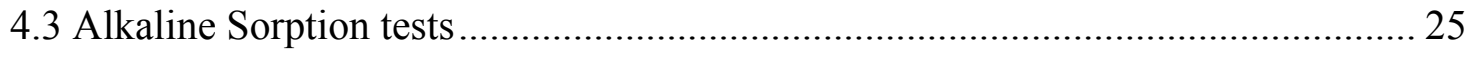

4.3.1 Sorption experiments on polymer/clay composites..................................... 25

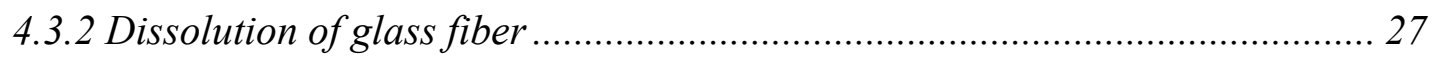

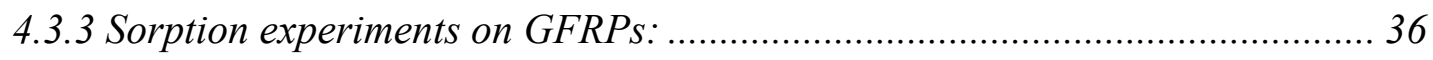

4.3.4 GFRP aging without any sustained load ............................................. 44

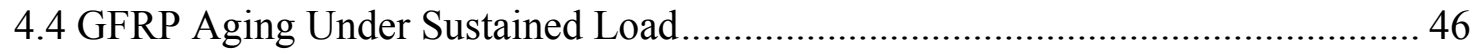

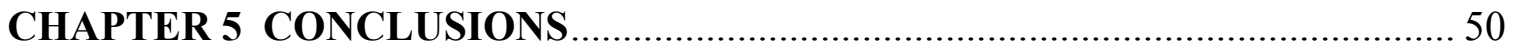

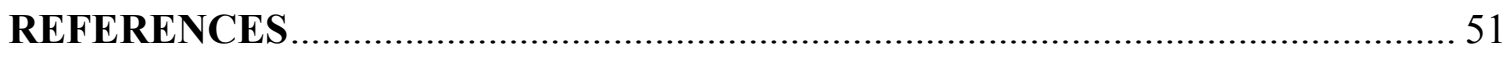

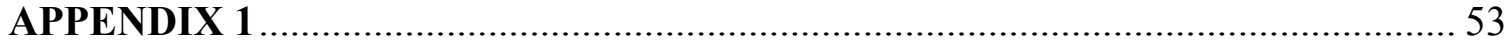




\section{LIST OF FIGURES}

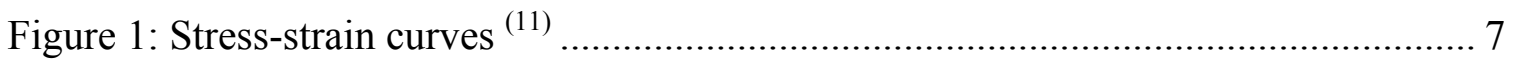

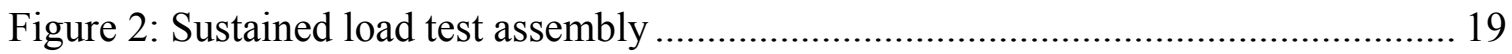

Figure 3. Weight gain \% versus time for neat resin samples..................................... 26

Figure 4. Weight gain \% versus time for vinyl ester samples with 1\% clay. ................. 27

Figure 5. Weight gain \% versus time for vinyl ester samples with $2 \%$ clay. .................. 28

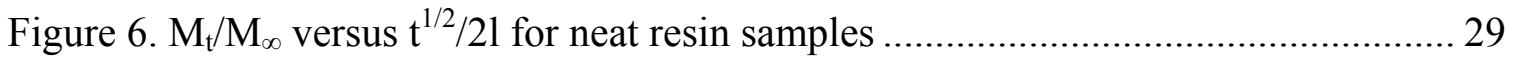

Figure $7 . \mathrm{M}_{\mathrm{t}} / \mathrm{M}_{\infty}$ versus $\mathrm{t}^{1 / 2} / 21$ for vinyl ester samples with $1 \%$ nanoclay ....................... 30

Figure $8 . \mathrm{M}_{\mathrm{t}} / \mathrm{M}_{\infty}$ versus $\mathrm{t}^{1 / 2} / 21$ for vinyl ester samples with $2 \%$ nanoclay ...................... 31

Figure 9. Dissolution of glass fiber mat in alkaline solution of $\mathrm{pH} 13.2$ at room

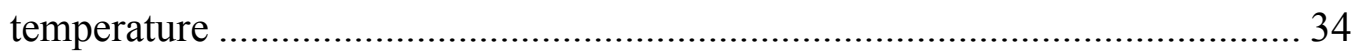

Figure 10. Weight gain \% versus time for GFRP composites with no clay .................... 36

Figure 11. Weight gain \% versus time for GFRP composites with 1\% clay .................. 37

Figure 12. Weight gain \% versus time for GFRP composites with $2 \%$ clay ................... 38

Figure 13. $M_{t} / M_{\infty}$ versus $t^{1 / 2} / 21$ for GFRP samples with no nanoclay .......................... 40

Figure 14. $\mathrm{M}_{\mathrm{t}} / \mathrm{M}_{\infty}$ versus $\mathrm{t}^{1 / 2} / 21$ for GFRP samples with $1 \%$ nanoclay .......................... 41

Figure 15. $\mathrm{M}_{\mathrm{t}} / \mathrm{M}_{\infty}$ versus $\mathrm{t}^{1 / 2} / 21$ for GFRP samples with $2 \%$ nanoclay ............................ 42 


\section{LIST OF TABLES}

Table 1. Fiber Volume Percentage and Void Fraction of Composites with No Clay...... 20

Table 2. Fiber Volume Percentage and Void Fraction of Composites with 1\% Clay ...... 21

Table 3. Fiber Volume Percentage and Void Fraction of Composites with 2\% Clay ...... 21

Table 4. Average Values of Void Fraction and Fiber Volume Percentage ..................... 21

Table 5. Young's modulus of Glass Fiber and Vinyl Ester Resin .................................. 22

Table 6. Estimates of the mechanical properties of GFRP composites using Law of

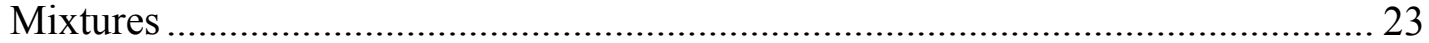

Table 7. Tension Test Results for GFRP composites with No Nanoclay ........................ 24

Table 8. Tension Test Results for GFRP composites with 1\% Nanoclay ........................ 24

Table 9. Tension Test Results for GFRP composites with 2\% Nanoclay ....................... 25

Table 10. Ultimate Moisture Content and Diffusion Coefficient of Vinyl EsterNanoclay Samples (Values in parentheses are standard deviations.) $\quad$.....26

Table 11: Diffusion coefficients of GFRP composites with Different Clay Loadings..... 37

Table 12. Residual Tensile Strength of GFRP composites with No Clay aged in Alkaline

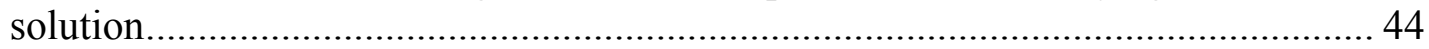

Table 13. Residual Tensile Strength of GFRP composites with $1 \%$ Clay aged in Alkaline

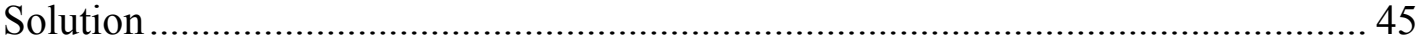

Table 14. Residual Tensile Strength of GFRP composites with $2 \%$ Clay aged in Alkaline

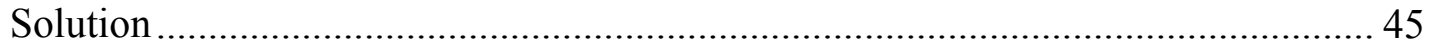

Table 15. Residual Tensile Strengths of GFRP composites aged in Alkaline Solution for 6 months (Values in parentheses are standard deviations.) ...................................... 46

Table 16. Residual Tensile Strength of GFRP composites with 0\% clay under Sustained Load in Alkaline Solution....

Table 17. Residual Tensile Strength of GFRP composites with 1\% clay under Sustained Load in Alkaline Solution .................................................................................. 47

Table 18. Residual Tensile Strength of GFRP composites with 2\% clay under Sustained Load in Alkaline Solution 48

Table 19: Reduction in Tensile Strength of GFRP composites under Sustained Load in Alkaline Solution (values in parentheses are standard deviations)..... 48 


\section{CHAPTER 1 INTRODUCTION}

Conventional structural materials like steel and aluminum have potential problems mainly because of their susceptibility to corrosion; particularly, the steel reinforcing bars (rebars) in Portland cement concrete are subject to corrosion when the concrete is in contact with moisture or solution containing deicing salt solutions. This type of corrosion could result in destruction of major structures like bridge decks, building columns, etc. To deal with this problem, many methods ${ }^{(1)}$ have been proposed, such as: 1) increase concrete cover over steel reinforcements, 2) use epoxy coated steel bars, 3) apply coatings on the steel bars, 4) use corrosion inhibitors in concrete, 5) cathodic protection, etc.

But one method that has gained prominence is the use of glass fiber reinforced polymer composites (GFRP composites) as reinforcing elements in concrete. They can be used in lieu of steel rebars in the concrete because of their numerous advantages in material properties such as: high stiffness-weight ratio, high strength-weight ratio, corrosion resistance, and ease in fabrication. GFRP bars were found to be more durable than steel reinforcements even in marine environment. These advantages have been instrumental in building a whole bridge deck out of GFRP composites. ${ }^{(2)}$

There are various ways in which FRPs are used to reinforce concrete $\left.{ }^{(1)}: 1\right)$ as rebars to replace normal reinforcing steel rebars, 2) as prestressing tendons, and 3) as wrapping to reinforce concrete externally. In the first case, Young's modulus, tensile strength and durability of GFRP bars in concrete are important factors. When GFRP bars are used as prestressing tendons, fatigue properties such as creep-rupture behavior are 
play an important role in the durability of the composites. Also when it is used as external wrappings, ductility and bond strength with concrete are major factors to be considered. $^{(1)}$

Carbon and glass fibers are the most commonly used fibers in FRPs, with glass fibers being preferred due to their competitive cost. In the manufacture of GFRP composites thermoset polymers like epoxy and vinyl ester polymers are preferred to thermoplastic polymers. This is due to the fact that thermoset polymers are more resistant to changes in temperature and have fewer voids than thermoplastic polymers.

However, GFRP composites are not without disadvantages. Long term performance of GFRP composites is not well known, which is a major impediment in their use in major constructional projects. The main problem that arises in the use of GFRP composites is the absorption of moisture from the atmosphere, which leads to delamination and fiber weakening. ${ }^{(3)}$ This severely affects the durability of GFRP composites. To reduce the absorption of moisture, composites are prepared by dispersing clay platelets of nanometer dimensions in the polymer matrix. This forms a nanocomposite, where the diffusing molecules encounter flake-like barriers, thereby reducing moisture diffusivity. ${ }^{(4)}$ The reduction of diffusivity in the neat resin and GFRP composites by adding clay platelets has been well documented. ${ }^{(4,5)}$

When we use GFRP composites as reinforcement in concrete, the main issue is the effect of the concrete pore solution on the durability of the composites. This pore solution is highly alkaline with $\mathrm{pH}$ of about 13.5 . This high $\mathrm{pH}$ concentration $(\sim 13.0)$ can be very harmful to GFRP composites. The glass fibers could be degraded rapidly in high $\mathrm{pH}$ concentrated solutions with loss of fiber strength and toughness. This degradation is 
due to the dissolution of glass fiber with alkaline solution and also the accumulation of reaction products between the fiber filaments. ${ }^{(6)}$ Also, the presence of calcium, potassium and sodium ions in the concrete pore solution helps to degrade glass fibers. ${ }^{(7)}$

The polymer matrix forms the first line of defense of the GFRP against corrosive environments. It offers a level of protection to glass fibers, but it cannot stop the eventual diffusion of the alkaline solution to the fiber. ${ }^{(8)}$ Over sufficient exposure time, the corrosive species will diffuse through the matrix to the fibers and attack them. Hence the diffusivity of the matrix plays an important role in the durability of the GFRP composites.

The present study uses GFRP composites made with E-glass fiber (about 55\% $\left.\mathrm{SiO}_{2}, 25 \% \mathrm{CaO}\right)^{(9)}$ and vinyl ester resin as the matrix. The objectives of the present study are to measure the diffusivity of alkaline solution through GFRP composites and polymer matrix with different clay loadings and to determine the aging of GFRP composites in alkaline environment with and without sustained load. 


\section{CHAPTER 2}

\section{THEORY}

There are two main phases in FRPs: the fiber phase which is the main load carrying component and the polymer matrix phase which binds the fibers together and through which the load is carried to the fiber phase.

\subsection{The Fiber Phase}

This is the main load carrying component of the FRP. Fibers can be in the form of filaments, strands or rovings. The different types of fibers that are in use are carbon fibers, glass fibers and aramid fibers. Glass fibers are the most economical fibers that can be used in composite applications. The other advantages are high tensile strength and excellent insulating properties. The limitations are low tensile modulus, sensitivity to abrasion, high hardness and low corrosion resistance in an alkaline environment. The different types of glass fibers are E-, Z-, A-, C-, and S- or R-glass fibers.

Silica is the main component of the E-glass fibers and when exposed to an alkaline environment, it reacts chemically with the hydroxyl ions as follows:

$$
\mathrm{SiO}_{2}+4 \mathrm{OH}^{-} \rightarrow \mathrm{SiO}_{4}^{4-}+2 \mathrm{H}_{2} \mathrm{O}
$$

The $\mathrm{SiO}_{4}{ }^{4-}$ ions form reaction products with the metal ions in the alkaline solution and these reaction products diffuse out from the composite. Some of the reaction products may also accumulate between the glass fibers which leads to weakening of the composite. 
Durability of GFRP composites depends on proper bonding between the glass fiber and the polymer matrix. Improper bonding could result in delamination and weakening of the composite. The inorganic glass fiber is not compatible with the organic matrix. Hence the glass fiber has to be treated on the surface with a coupling agent (sizing material) to promote better bonding. The coupling agent has a general formula of $\mathrm{RSiX}_{3}$, where $\mathrm{R}$ is the organic group that is compatible with the polymer and $\mathrm{X}$ is any hydrolysable group such as an alcohol that is compatible with the glass fiber. ${ }^{(5)}$

\subsection{The Resin Phase}

Selection of proper resin is a major item to attain adequate durability of the GFRP bars because the resin is the first line of defense against any corroding medium. Even though the resin does not impart any significant strength to the GFRP composite, they help in distributing the load to the fibers. Hence the role of the resin is to (i) maintain the orientation of the fibers, (ii) distribute the load to the fibers (iii) protect the fibers from the diffusing species and mechanical abrasion and (iv) reduce glass fiber brittleness.

Resins are categorized into two major types: thermoplastic resins and thermoset resins. The most common thermoplastic resins like polyethylene, polypropylene and PVC are basically linear molecules that polymerize primarily by addition polymerization. Other thermoplastics like Nylon, polycarbonates etc are also used in FRPs and they polymerize by condensation polymerization. Thermoplastics do not have any random crosslinks. They can be reshaped upon altering the temperature. The advantages of thermoplastic resins include longer life, ease of handling and recyclability. However, the major limitation is their high viscosity which makes them difficult to process. 
Thermoset resins are crosslinked molecules which cannot be reshaped once the cross links have been formed. They have lower viscosity than thermoplastics and hence are much easier to process. Also the void content of composites using polymers formed by thermoset resins is lesser than those formed with thermoplastic resins. They also provide better bonding between the glass fiber and the matrix. All these advantages make thermoset reins better suited for production of more durable GFRP composites.

The common thermoset resins used for GFRP composites are vinyl esters, epoxies, unsaturated polyesters, poly-urethanes and phenolics. Among these, vinyl ester resins have better corrosion resistance, higher fracture toughness, easier fabrication, low viscosity and faster curing times than other thermoset resins. Vinyl ester resins typically contain various proportions of styrene (35\%-50\%) to act as crosslinking agents. Although vinyl ester resins have many advantages, they are not immune to harsh environments like saline, freeze-thaw and alkaline conditions. It has been proved that urethane modified vinyl ester composites perform much better than the vinyl ester resins themselves. ${ }^{(10)}$

The effect of alkaline solutions on the polymer matrix itself can be quite severe. It has been shown that exposure to alkaline solution causes the most weakening of vinyl ester polymer as compared to acid and brine solutions and that the reduction in mechanical properties was mainly due to the matrix weakening and fiber-matrix debonding. ${ }^{(3)}$ 


\subsection{Stress-Strain Characteristics}

Figure 1 shows two different types of stress-strain relationships. Curve $\mathrm{ABC}$ is a general curve that is characteristic of metals and most plastics. The initial linear part $\mathrm{AB}$ represents elastic deformation, since any change in dimension that the material undergoes in this region is reversed back to the original dimensions once the stresses are removed. This linear relationship between the stress and the strain is given by Hooke's law. The slope of the curve for the elastic deformation is called the Young's modulus. The part $\mathrm{BC}$ of the curve represents plastic deformation where the release of stresses does not revert the material to its original dimensions. In this region, once the material is deformed it stays deformed. This plastic deformation is useful in shaping materials by simple mechanical operations.

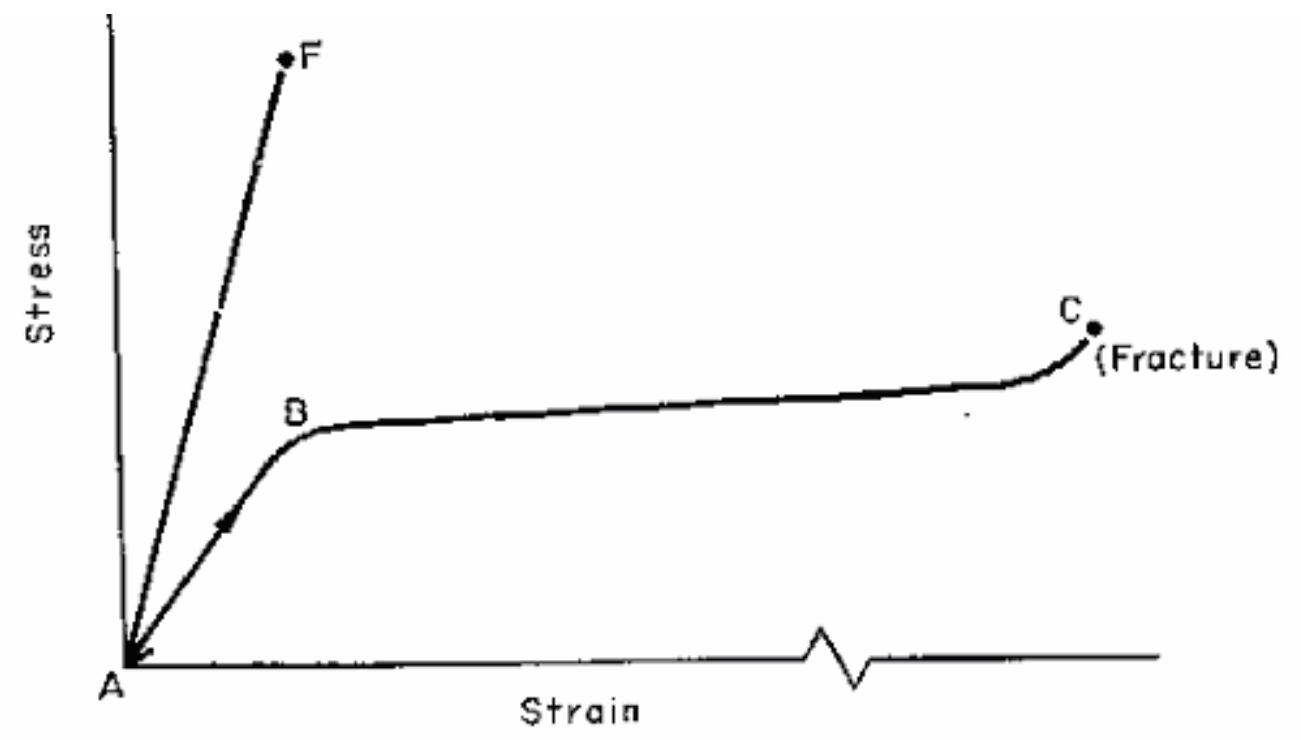

Figure 1. Stress-strain curves ${ }^{(11)}$

The curve AF is characteristic of many reinforced materials like composites. These materials show little or no plastic deformation at room temperature. Hence simple 
mechanical operations cannot be used to shape these materials and different forming methods should be applied.

\subsection{Nanocomposites}

It has been discussed that the diffusion of corroding agents like moisture or alkaline solution causes serious damage and weakening to the durability of the GFRP composites. To restrict this ingress of corroding medium, the diffusion coefficient of the GFRP composites must be reduced. This may be achieved by the addition of nano-sized clay platelets (or nanoclay) to the polymer matrix. Addition of small amounts of nanoclay has shown to reduce moisture/ chemical diffusivity much. ${ }^{(4,5)}$

Depending on the extent of dispersion of the nanoclay inside the polymer matrix, the nanocomposites are classified as conventional composites, intercalated nanocomposites and delaminated nanocomposites. ${ }^{(12)}$ In conventional composites, the clay particles are in the form of aggregates with no proper dispersion of the clay. The intercalated nanocomposites show better dispersion with the polymer matrix being inserted between clay layers. The delaminated nanocomposites or exfoliated nanocomposites show the best dispersion with clay layers of only $1 \mathrm{~nm}$ thickness being dispersed in the polymer matrix. This is the best case as it leads to maximum polymerclay interaction and hence maximum changes in the properties of the composite. Interfacial areas of clay particles up to $700 \mathrm{~m}^{2} / \mathrm{cm}^{3}$ can be reached by uniform dispersion of nanoclay. ${ }^{(13)}$ Good dispersion of the clay can also be attained by proper selection of curing agent. Studies have shown that intercalated epoxy nanocomposites were obtained 
with diethylenetriamine, a curing agent while exfoliated epoxy nanocomposites were obtained with tung oil anhydride..$^{(14)}$

\subsection{Nanoclay}

Nanoclays are primarily layered silicates which include both natural clays such as montmorillonite and synthetic clays such as magadite, laponite and fluorodectorite. ${ }^{(12)}$ Montmorillonite is most widely used because of its flat plate like structure and high aspect ratio. This gives rise to a high surface area which increases the clay-polymer interaction.

Clays are hydrophilic in nature and so are not compatible with the polymer matrix. They can be made compatible by using compatibilizing agents which function similarly to a detergent. The most popular compatibilizing agent is alkyl ammonium ion.

The criteria for good polymer-filler bonding are: ${ }^{(15)}$

- Low contact angle between polymer and filler

- Low viscosity of resin at the time of application

- High viscosity after application

- Similar coefficients of thermal expansion of polymer and filler

- Clean, dust free, crack free filler surface

\subsection{Diffusion in Nanocomposites}

The diffusion characteristics of vinyl ester-nanoclay nanocomposites have been studied extensively. ${ }^{(4,5)}$ The Fick's second law is given as, 


$$
\frac{\partial c}{\partial t}=D \frac{\partial^{2} c}{\partial x^{2}}
$$

where

$\mathrm{c}=$ concentration of diffusing species at time $\mathrm{t}$

$\mathrm{D}=$ diffusion coefficient or diffusivity

The solution of Equation (2) will give the mass uptake $\mathrm{M}_{t}$ of a thin polymer film in humid conditions. This is given by ${ }^{(16)}$

$$
\frac{M_{t}}{M_{\infty}}=\left[1-\sum_{0}^{\infty} \frac{8}{(2 n+1)^{2} \pi^{2}} \exp \left[\frac{-D(2 n+1)^{2} \pi^{2} t}{4 l^{2}}\right]\right]
$$

where

$\mathrm{M}_{\mathrm{t}}=$ mass uptake at time $\mathrm{t}$,

$\mathrm{M}_{\infty}=$ ultimate mass uptake

$l=$ half the thickness of the polymer film.

Equation (3) can be rewritten as,

$$
\frac{M_{t}}{M_{\infty}}=2\left(\frac{D t}{l^{2}}\right)^{1 / 2}\left\{\pi^{-1 / 2}+2 \sum_{1}^{\infty}(-1)^{n} \text { ierfc } \frac{n l}{\sqrt{D t}}\right\}
$$

For short times, Equation (4) can be simplified into the form ${ }^{(17)}$

$$
\frac{M_{t}}{M_{\infty}}=\left(4 \sqrt{\frac{D}{\pi}}\right) * \frac{\sqrt{t}}{2 * l}
$$

A plot of $\frac{M_{t}}{M_{\infty}}$ vs $\frac{t^{1 / 2}}{2 l}$ is linear at the initial stage and the diffusivity can be calculated from its slope. 


\subsection{Effect of Clay Loading on Diffusivity}

It has been shown that the presence of moisture can plasticize a polymer and lower the glass transition temperature ${ }^{(18)}$ which results in softening of the polymer and thus enhancement of creep deformations. If the polymer has not been fully cured the glass transition temperature is lowered upon contact with moisture which results in further curing of the polymer It has been proved that the water mobility and the polymer chain mobility increase almost threefold when the polymer is in the 'rubbery state'. Hence when the glass transition temperature, $\mathrm{Tg}$ decreases, the moisture diffusivity of the polymer increases. Another effect due to the presence of moisture is the build-up of internal stresses caused by the swelling of the polymer, resulting in microcracks. ${ }^{(3)}$ In the case with GFRP composites this swelling can cause delamination and debonding.

The effect of clay loading on the diffusivity of moisture through the polymer-clay composites has been documented. ${ }^{(4,5)}$ It has been found that the diffusivity is reduced to one fourth of its original value with the addition of $2.5 \mathrm{wt} \%$ of clay ${ }^{(4)}$ and by up to $92 \%$ with the addition of $5 \mathrm{wt} \%$ clay. ${ }^{(5)}$ This is thought to be due to the barrier effect that the clay poses to the diffusing species. The diffusing species must travel a longer path through the polymer matrix because of the barrier posed by the clay platelets. This decreases the diffusion coefficient of the GFRP and hence may retard the aging. However, the mechanical properties of GFRP composites are not affected by the addition of nanoclay since the glass fiber is the main contributor to the properties of the composite. But in the case with polymer-clay composites without fiber, addition of nanoclay improves the mechanical properties like Young's modulus. ${ }^{(19)}$ 
There is a different view from the above concept as to the role of nanoclay as a diffusion barrier. Some researchers have shown that addition of nanoparticles actually enhances the diffusion in few polymer systems. ${ }^{(20)}$ These polymer systems are high permeability polymers such as copolymer of tetrafluoroethylene (TFE) and bis (trifluoromethyl)-4,5-difluoro-1,3-dioxole (PDD), characterized by regions of high free volume leading to their high permeability. Addition of fumed silica nanoparticles to the TFE/PDD system disrupts the polymer packing, which results in an increase in free volume in the polymer and thus an increase in diffusivity. 


\section{CHAPTER 3}

\section{EXPERIMENTAL}

\subsection{Materials}

Derakane $^{\mathrm{TM}}$ 411-350 epoxy vinyl ester resin obtained from Dow Chemical Co., was used for the preparation of the GFRP samples. It contained dissolved styrene by 45 $\mathrm{wt} \%$. Curing of this resin was achieved at room temperature using an initiator catalyst, methyl ethyl ketone peroxide and a promoter, cobalt naphthenate. Both chemicals were obtained from Sigma-Aldrich Company.

E-glass fiber mats were obtained from Vectorply Corp. and used as reinforcing fibers in the GFRP composites. These mats are woven $0^{\circ} / 90^{\circ}$ bi-directional and have a density of $543 \mathrm{~g} / \mathrm{m}^{2}$. The thickness of the fiber mats is $0.12 \mathrm{~cm}$.

Cloisite $^{\circledR} 10 \mathrm{~A}$, supplied from Southern Clay Products, Inc., was used in preparing the nanocomposites. It is natural (montmorillonite) clay modified with quaternary ammonium salts. Cloisite ${ }^{\circledR} 10 \mathrm{~A}$ contains $39 \mathrm{wt} \%$ of organic material.

\subsection{Sample Preparation}

The composite samples were prepared by hand lay-up technique. Plain GFRP samples were prepared with 2 layers of E-glass fiber. One hundred and twenty grams of vinyl ester monomer was mixed with $1 \mathrm{wt} \%$ of the initiator and $0.03 \mathrm{wt} \%$ of the promoter, and degassed for a few minutes. A part of this mixture was poured onto an aluminum plate and a sheet of glass fiber of dimensions $31.75 \mathrm{~cm}$ x $15.87 \mathrm{~cm}$ was placed on top of it. More resin was poured and spread on the fibers till the fibers were wet completely by the resin. A second layer of glass fibers of the same dimensions was 
placed on top of this and again more resin was poured and spread till the glass fiber was completely wet. Another aluminum plate was placed on top and three lead blocks weighing $26.3 \mathrm{~kg}$ in total were placed on the aluminum plate to squeeze out excess resin and air bubbles. This preparation was conducted at room temperature for 24 hours in order to cure the samples. GFRP composite plates of dimensions $31.75 \mathrm{~cm} \mathrm{x} 15.87 \mathrm{~cm} \mathrm{x}$ $0.13 \mathrm{~cm}$ were thus prepared and were further post-cured in an oven for $3 \mathrm{hrs}$ at $100^{\circ} \mathrm{C}$. Finally each sample plate was cut to almost equal size of $29.21 \mathrm{~cm}$ x $2.54 \mathrm{~cm}$ x $0.13 \mathrm{~cm}$ using a tile saw.

Nano-GFRP samples were prepared by the same method except for the addition of clay. Prior to adding the initiator and promoter to the resin, the nanoclay $(1 \mathrm{wt} \%$ or 2 wt $\%$ ) was added. The resin was stirred using a mechanical stirrer while the clay was added bit by bit manually. Stirring was continued for 2 hours to allow the clay to disperse well in the resin. During this process, the container top was covered with an aluminum foil to prevent the evaporation of styrene. Also, the container was placed on an ice block to reduce the heating effect due to stirring. After stirring, the clay-dispersed resin was degassed for a few minutes and then the initiator and catalyst were added. Nano-GFRP composite samples were then prepared by the same method as described before.

\subsection{Characterization Tests}

The void fraction and the fiber volume percentage of the prepared composite samples were determined as described below. The fiber volume fraction was determined by the ignition loss method according to ASTM D2584. ${ }^{(21)}$ Sample pieces with 
dimensions of $2.54 \mathrm{~cm} \times 2.54 \mathrm{~cm}$ were cut from each GFRP plate and used for these tests. The weight and volume of the sample pieces were first recorded. Then the samples were placed in crucibles and ignited in a muffle furnace at $575{ }^{\circ} \mathrm{C}$ till only the fiber remained. The crucibles were taken out and cooled in a desiccator and then weighed. The weight loss due to the ignition enabled the computation of the fiber volume fraction. The density of the glass fiber was taken as $2.565 \mathrm{~g} / \mathrm{cm}^{3}$. The fiber volume fraction was calculated by

$$
F=\frac{W_{g}}{d_{g} * v_{s}} * 100
$$

where

$\mathrm{F}=$ fiber volume percent, vol\%

$\mathrm{W}_{\mathrm{g}}=$ weight of the glass fibers, $\mathrm{g}$

$\mathrm{d}_{\mathrm{g}}=$ density of the glass fibers, $\mathrm{g} / \mathrm{cm}^{3}$

$\mathrm{v}_{\mathrm{s}}=$ volume of the sample, $\mathrm{cm}^{3}$

ASTM D $2734^{(22)}$ was used to determine the void fraction of the sample pieces.

The void fraction is given by the equation

$$
V=100-M_{d}\left(\frac{r}{d_{r}}+\frac{g}{d_{g}}+\frac{c}{d_{c}}\right)
$$

where

$\mathrm{V}=$ void fraction of the GFRP sample, vol\%

$M_{d}=$ measured density of the GFRP sample, $\mathrm{g} / \mathrm{cm}^{3}$

$r=$ weight $\%$ of resin in the GFRP sample

$\mathrm{g}=$ weight $\%$ of glass fiber in the GFRP sample

$\mathrm{c}=$ weight $\%$ of nanoclay in the GFRP sample 
$\mathrm{d}_{\mathrm{r}}=$ density of the resin $\left(1.14 \mathrm{~g} / \mathrm{cm}^{3}\right)$

$\mathrm{d}_{\mathrm{g}}=$ density of the glass fibers $\left(2.565 \mathrm{~g} / \mathrm{cm}^{3}\right)$

$\mathrm{d}_{\mathrm{c}}=$ density of the nanoclay $\left(1.9 \mathrm{~g} / \mathrm{cm}^{3}\right)$

\subsection{Tension Tests}

Tension tests were conducted to measure Young's modulus and the tensile strength of the GFRP samples. Tapered tabs $(5.08 \mathrm{~cm} \times 2.54 \mathrm{~cm})$ were attached to both ends of every sample to reinforce them, as per ASTM D3039. ${ }^{(23)}$ A two-part epoxy adhesive, Elementis 7895 , was used to glue the tabs to the samples. The adhesive was allowed to cure for a day before the tests were conducted.

The modulus of elasticity and the tensile strength were measured using a stressstrain instrument, INSTRON 8501. Before testing, average cross-sectional area of each sample was measured. An extensometer with 2.54-cm gage length was connected to the middle of the sample to measure the strain values. Each sample was stressed to about $1750 \mathrm{~N}$ for Young's modulus measurements. The stress was then released and another measurement was made to check the reproducibility of the data.

The extensometer was then removed and the sample was stressed till it failed. The load at which a test sample failed was used to calculate the tensile strength of the GFRP composites in MPa.

\subsection{Alkaline Sorption Tests}

Tests were conducted to study: a) absorption characteristics of GFRP composites b) absorption characteristics of resin samples without any glass fiber and c) dissolution characteristics of the glass fiber, all in an alkaline solution. 
3.5.1 Sorption tests on GFRP composites: A total of 36 samples (12 each from plain GFRP and GFRP composites with $1 \%$ and $2 \%$ clay) of dimensions $29.21 \mathrm{~cm} \times 2.54 \mathrm{~cm} \mathrm{x}$ $0.13 \mathrm{~cm}$ were used for this test. The alkaline solution used in these tests was a mixture of $0.32 \mathrm{M} \mathrm{NaOH}, 0.17 \mathrm{M} \mathrm{KOH}$ and $0.07 \mathrm{M} \mathrm{Ca}(\mathrm{OH})_{2} \cdot{ }^{(24)} \mathrm{The} \mathrm{pH}$ of this alkaline solution was found to be 13.2. The samples were then kept immersed in the alkaline solution in three containers. Each container held 12 samples of either plain, $1 \%$ or $2 \%$ samples immersed in 4 liters of alkaline solution. Among the 12 samples in each container, three samples were randomly chosen, taken out regularly timed intervals, wiped with blotting paper, dried under an infrared light, weighed and returned to the box. Weight measurements were taken initially at 1 day intervals for a period of 4 weeks and then in intervals of 1 week. The tests were carried out up to 6 months. The weight measurements enabled one to study the weight gain of the samples as a function of time. The diffusion coefficients of the GFRP samples were then determined.

3.5.2 Sorption tests on polymer samples without glass fiber: Vinyl ester polymer samples (containing no glass fiber) without and with nanoclay (1\% and 2\%) were prepared and cured in the same manner as GFRP composites. Four samples each containing no clay, $1 \%$ clay and $2 \%$ clay (twelve in total) were kept immersed in 2 liters of the alkaline solution in a container. Weight gain of the samples was measured daily with the same method as described previously. 
3.5.3 Dissolution of glass fiber: A 4.45-cm square piece of the E-glass fiber mat was immersed in one liter of the alkaline solution. The piece was taken out, washed, dried and weighed at one-week intervals. The weight loss of the fiber piece was determined from these measurements.

\subsection{Sustained Load Tests}

A cylindrical reservoir was prepared to hold the alkaline solution together with a GFRP composite sample. A $2.54-\mathrm{cm}$ slit was cut at the center of a $5.08-\mathrm{cm}$ diameter rubber cap. The cap was then attached at approximately $5.25 \mathrm{~cm}$ from one end of the GFRP composite sample. The contact area between the sample and the rubber cap was sealed by applying layers of epoxy adhesive, vinyl ester resin and a mixture of resin and epoxy adhesive. Both ends of the sample were then reinforced by attaching $2.54-\mathrm{cm} \mathrm{x}$ 5.08-cm tabs. A PVC pipe (5.08 cm O.D. and $19.05 \mathrm{~cm} \mathrm{long)} \mathrm{was} \mathrm{fitted} \mathrm{tightly} \mathrm{to} \mathrm{this}$ assembly so that it forms a water-tight reservoir to hold the alkaline solution and the GFRP sample. Then a sustained load was applied by tightening a die spring. ${ }^{(25)}$ The spring was $4.45 \mathrm{~cm}$ long and $2.54 \mathrm{~cm}$ in diameter and had a maximum load capacity of $5350 \mathrm{~N}$. Each spring was tested for load-contraction relationship and the spring constant was determined. Two 8-mm holes were drilled through the center of each end of each test sample to latch them to the frame using a pin. A load of $1335 \mathrm{~N}(18.75 \%$ of the tensile strength of the GFRP composites) was applied on the samples by tightening the springs. After the load was applied, $350 \mathrm{ml}$ of the alkaline solution was poured into the PVC pipe, before sealing the pipe at the top using duct tape and glue. The whole assembly is shown in Figure 2. 


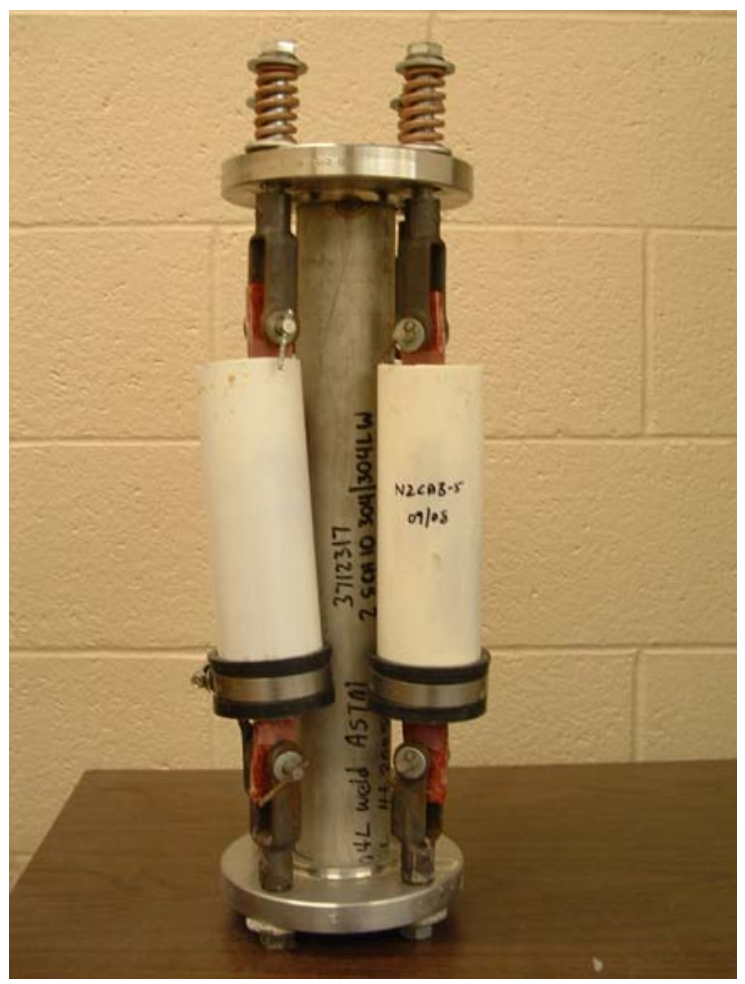

Figure 2. Sustained load test assembly

A total of 32 samples were used for this test (11 plain samples, 10 samples with $1 \%$ clay and 11 samples with $2 \%$ clay).

\subsection{Reduction in Tensile Strength of Aged GFRP composites}

The test samples with and without sustained load were monitored for six months. The aged GFRP composites from these tests were then subjected to tension failure and the residual tensile strength was determined. The data were used to determine the reduction in tensile strength due to aging. 


\section{CHAPTER 4}

\section{RESULTS AND DISCUSSION}

\subsection{Characterization Tests}

Tables 1,2 and 3 show the values of the void fraction and fiber volume percentage of plain GFRP composites and GFRP composites with $1 \%$ and $2 \%$ nanoclay, respectively. The fiber volume content is found to be fairly consistent from sample to sample. However, the void fractions of the plain samples, are higher than a typical void fraction of commercially prepared GFRP composites with about about 1 vol \%. This may be due to the manual method (hand lay-up method) used in this study for sample preparation. The average values of the void fraction and fiber volume percentage are given in Table 4. The values in parentheses give the standard deviations. The average void fraction is found to decrease slightly with increasing clay content. This is understandable as clay acts as a filler material and thereby reduces the voids in the samples.

Table 1. Fiber Volume Percentage and Void Fraction of Composites with No Clay

\begin{tabular}{|c|c|c|}
\hline Sample & $\begin{array}{c}\text { Fiber } \\
\text { vol\% }\end{array}$ & $\begin{array}{c}\text { Void } \\
\text { fraction } \\
\text { (vol\%) }\end{array}$ \\
\hline N2M-5 & 33.86 & 2.33 \\
\hline N2N-5 & 32.25 & 2.44 \\
\hline N2O-5 & 31.60 & 3.55 \\
\hline N2P-5 & 34.88 & 2.73 \\
\hline N2Q-5 & 36.52 & 3.11 \\
\hline N2R-4 & 35.22 & 3.86 \\
\hline N2S-3 & 33.81 & 2.15 \\
\hline N2T-3 & 38.27 & 2.24 \\
\hline
\end{tabular}


Table 2. Fiber Volume Percentage and Void Fraction of Composites with 1\% Clay

\begin{tabular}{|c|c|c|}
\hline Sample & $\begin{array}{c}\text { Fiber } \\
\text { vol\% }\end{array}$ & $\begin{array}{c}\text { Void } \\
\text { fraction } \\
\text { (vol \%) }\end{array}$ \\
\hline N2CU-5 & 36.75 & 1.56 \\
\hline N2CV-5 & 35.86 & 1.65 \\
\hline N2CW-5 & 35.86 & 1.57 \\
\hline N2CY-5 & 36.68 & 0.76 \\
\hline N2CZ-3 & 40.18 & 1.78 \\
\hline N2CAA-5 & 36.24 & 0.98 \\
\hline N2CAG-5 & 39.39 & 1.11 \\
\hline N2CAF-5 & 37.26 & 0.85 \\
\hline
\end{tabular}

Table 3. Fiber Volume Percentage and Void Fraction of Composites with 2\% Clay

\begin{tabular}{|c|c|c|}
\hline Sample & $\begin{array}{c}\text { Fiber } \\
\text { vol\% }\end{array}$ & $\begin{array}{c}\text { Void } \\
\text { fraction } \\
\text { (vol\%) }\end{array}$ \\
\hline N2CF-5 & 34.07 & 1.38 \\
\hline N2CK-5 & 39.72 & 1.10 \\
\hline N2CC-5 & 34.12 & 1.11 \\
\hline N2CH-5 & 37.58 & 0.36 \\
\hline N2CS-5 & 36.29 & 0.41 \\
\hline N2CO-1 & 42.11 & 0.77 \\
\hline N2CQ-1 & 36.52 & 0.32 \\
\hline N2CR-5 & 36.56 & 1.11 \\
\hline
\end{tabular}

Table 4. Average Values of Void Fraction and Fiber Volume Percentage (Values in parentheses are standard deviations.)

\begin{tabular}{|c|c|c|}
\hline $\begin{array}{c}\text { \% of } \\
\text { clay }\end{array}$ & $\begin{array}{c}\text { Average Fiber } \\
\text { volume \% }\end{array}$ & $\begin{array}{c}\text { Average Void } \\
\text { Fraction (vol \%) }\end{array}$ \\
\hline 0 & $34.6(2.2)$ & $2.8(0.6)$ \\
\hline 1 & $37.3(1.6)$ & $1.3(0.4)$ \\
\hline 2 & $37.2(2.7)$ & $0.8(0.4)$ \\
\hline
\end{tabular}




\subsection{Tension Tests}

The theoretical values of the Young's modulus of the GFRP composite can be estimated by the rule of mixtures. For a GFRP containing a unidirectional fiber, the rule of mixtures ${ }^{(14)}$ is given by

$$
E_{C}=E_{R} * V_{R}+E_{G} * V_{G}
$$

where

$\mathrm{E}_{\mathrm{C}}=$ Young's modulus of composite

$E_{R}=$ Young's modulus of resin

$\mathrm{E}_{\mathrm{G}}=$ Young's modulus of glass fiber

$\mathrm{V}_{\mathrm{R}}=$ volume percentage of resin

$\mathrm{V}_{\mathrm{G}}=$ volume percentage of glass fiber in the longitudinal direction

The volume of the fiber aligned with the direction of the stress applied is $57 \%$ of the total volume of the fiber. Therefore, Equation 9 becomes

$$
E_{C}=E_{R} * V_{R}+E_{G} *\left(V_{g} * 0.57\right)
$$

Table 5 shows the Young's modulus of the glass fiber and the resin. The modulus of the resin increases marginally with the addition of clay. ${ }^{(4)}$

Table 5. Young's modulus of Glass Fiber and Vinyl Ester Resin

\begin{tabular}{|c|c|}
\hline Component & $\begin{array}{c}\text { Young's modulus } \\
\text { (GPa) }\end{array}$ \\
\hline Glass fiber & 70.0 \\
\hline Neat Resin & 3.2 \\
\hline Resin $+1 \%$ Clay & 3.6 \\
\hline Resin $+2 \%$ Clay & 3.7 \\
\hline
\end{tabular}


The tensile strength of the composite can be estimated using the following equations:

$$
\sigma_{C}=\min \left\{\sigma_{G}\left(V_{G}+\frac{E_{R}}{E_{G}}\left(1-V_{G}\right)\right), \sigma_{R}\left(\frac{E_{G}}{E_{R}} * V_{G}+\left(1-V_{R}\right)\right)\right\}
$$

where

$\sigma_{\mathrm{G}}=$ Ultimate tensile strength of the glass fiber $=3500 \mathrm{MPa}$

$\sigma_{\mathrm{R}}=$ Ultimate tensile strength of the resin $=86 \mathrm{MPa}$

Equation 11 holds good for uni-directional fibers. For bi-directional fibers, the transverse fibers have a stress concentration effect that will affect the strength of the fiber mat. Hence a stress concentration factor has to be introduced in Equation 11 to properly estimate the tensile strength. This factor would depend on the fabric used, the preparation method, etc. The mechanical properties of GFRP composites used in this study are estimated according to Equations 10 and 11 and listed in Table 6. A stress concentration factor of 0.5 was used in Equation 11.

Table 6. Estimates of the mechanical properties of GFRP composites using Law of Mixtures

\begin{tabular}{|c|c|c|}
\hline \% clay & Young's modulus (GPa) & Tensile Strength (MPa \\
\hline 0 & 16.4 & 217.8 \\
\hline 1 & 17.0 & 208.8 \\
\hline 2 & 17.2 & 204.5 \\
\hline
\end{tabular}

Tension tests were conducted with INSTRON 8501 at an elongation rate of 0.254 $\mathrm{mm} / \mathrm{s}$ for Young's modulus measurements and $0.127 \mathrm{~mm} / \mathrm{s}$ for tensile strength measurements. Tables 7, 8 and 9 provide the Young's modulus and tensile strength of GFRP composites with $0 \%, 1 \%$ and $2 \%$ nanoclay, respectively. 
Table 7. Tension Test Results for GFRP composites with No Nanoclay

\begin{tabular}{|c|c|c|}
\hline Sample & $\begin{array}{c}\text { Young's modulus } \\
\text { (GPa) }\end{array}$ & $\begin{array}{c}\text { Tensile strength } \\
\text { (MPa) }\end{array}$ \\
\hline N2A-1 & 13.70 & 228.02 \\
\hline N2A-2 & 12.10 & 183.82 \\
\hline N2A-3 & 13.04 & 217.61 \\
\hline N2A-4 & 12.60 & 202.71 \\
\hline N2A-5 & 13.54 & 222.39 \\
\hline N2C-1 & 13.76 & 181.31 \\
\hline N2C-2 & 14.08 & 208.15 \\
\hline N2C-3 & 13.48 & 212.97 \\
\hline N2C-4 & 13.83 & 197.22 \\
\hline N2C-5 & 12.82 & 203.52 \\
\hline Average & $\mathbf{1 3 . 3 0}$ & $\mathbf{2 0 5 . 7 7}$ \\
\hline STD & $\mathbf{0 . 6 3}$ & $\mathbf{1 5 . 4 1}$ \\
\hline
\end{tabular}

Table 8. Tension Test Results for GFRP composites with 1\% Nanoclay

\begin{tabular}{|c|c|c|}
\hline Sample & $\begin{array}{c}\text { Young's Modulus } \\
\text { (GPa) }\end{array}$ & $\begin{array}{c}\text { Tensile strength } \\
\text { (MPa) }\end{array}$ \\
\hline N2CA-1 & 13.74 & 198.80 \\
\hline N2CA-2 & 14.13 & 187.84 \\
\hline N2CA-3 & 12.59 & 212.75 \\
\hline N2CA-4 & 12.99 & 186.74 \\
\hline N2CA-5 & 13.56 & 206.99 \\
\hline N2CAH-4 & 14.71 & 223.62 \\
\hline N2CAH-5 & 14.00 & 210.09 \\
\hline N2CAI-4 & 14.02 & 215.47 \\
\hline N2CAI-5 & 13.95 & 223.39 \\
\hline Average & $\mathbf{1 3 . 7 5}$ & $\mathbf{2 0 7 . 3 0}$ \\
\hline STD & $\mathbf{0 . 6 3}$ & $\mathbf{1 3 . 7 1}$ \\
\hline
\end{tabular}


Table 9. Tension Test Results for GFRP composites with 2\% Nanoclay

\begin{tabular}{|c|c|c|}
\hline \multirow{2}{*}{ Sample } & $\begin{array}{c}\text { Young's Modulus } \\
\text { (GPa) }\end{array}$ & $\begin{array}{c}\text { Tensile Strength } \\
\text { (MPa) }\end{array}$ \\
\cline { 2 - 3 } N2CD-1 & 14.94 & 241.52 \\
\hline N2CD-2 & 13.33 & 195.91 \\
\hline N2CD-3 & 13.86 & 216.53 \\
\hline N2CD-4 & 14.38 & 215.84 \\
\hline N2CD-5 & 13.48 & 191.11 \\
\hline N2CE-1 & 15.45 & 210.12 \\
\hline N2CE-2 & 14.31 & 219.47 \\
\hline N2CE-3 & 14.48 & 212.61 \\
\hline N2CE-4 & 15.15 & 232.21 \\
\hline Average & $\mathbf{1 4 . 3 8}$ & $\mathbf{2 1 5 . 0 4}$ \\
\hline STD & $\mathbf{0 . 7 3}$ & $\mathbf{1 5 . 7 6}$ \\
\hline
\end{tabular}

Tables 7,8 and 9 reveal that the actual values of the mechanical properties are lower than the estimated values. This is due to the inconsistencies developed in the sample during the preparation process. Also the application of load leads to cracking and debonding which will also affect the mechanical properties of the composite. Further, incomplete curing of the resin may also lead to lower strength values.

\subsection{Alkaline Sorption Tests}

\subsubsection{Sorption experiments on polymer-clay composites:}

Figures 3, 4 and 5 show the results of sorption experiments of alkaline solution of $\mathrm{pH} 13.2$ onto vinyl ester polymer samples containing $0 \%, 1 \%$ and $2 \%$ clay, respectively. Weight measurements were made on a daily basis for about a month. It can be seen that the weight gain for each category varies over a wide range as seen particularly from Figures 3 and 5. This may be due to the large variation of void fractions within the same 
category of sample (see Tables 1 through 3). Also, from these weight gain characteristics, we find that the ultimate weight gain does not vary much with the clay content in the resin. During these tests, a white substance was observed on the surface of the polymer samples. This was observed in previous studies also ${ }^{(5)}$ and thought to be the reaction product between the vinyl ester resin and the alkaline solution. One interesting observation here is that there seemed to be more reaction product on the surface of the samples containing clay than on the samples containing no clay. This phenomenon cannot be explained at this time. The white substance could also be the reaction product between the clay and the alkaline solution.

Figures 6, 7 and 8 depict the plot of $\frac{M_{t}}{M_{\infty}}$ vs $\frac{t^{1 / 2}}{2 l}$ for polymer composites with $0 \%, 1 \%$ and $2 \%$ clay, respectively. The initial slopes of the plots were used to determine the diffusion coefficients. Table 10 provides the average diffusion coefficients and the average ultimate weight gain values at different clay loadings of the polymer clay samples.

Table 10. Ultimate Moisture Content and Diffusion Coefficient of Vinyl EsterNanoclay Samples (Values in parentheses are standard deviations.)

\begin{tabular}{|c|c|c|}
\hline$\%$ clay & $\begin{array}{c}\text { Ultimate Moisture content } \\
(\%)\end{array}$ & $\begin{array}{c}\text { Average D }(\mathrm{x} \\
\left.10^{9} \mathrm{~cm}^{2} / \mathrm{s}\right)\end{array}$ \\
\hline $0 \%$ & $0.88(0.06)$ & $4.76(0.51)$ \\
\hline $1 \%$ & $0.76(0.02)$ & $3.87(0.21)$ \\
\hline $2 \%$ & $0.92(0.08)$ & $3.24(0.28)$ \\
\hline
\end{tabular}

From Table 10, one can see that the diffusion coefficient decreases with increasing clay content. This is consistent with the findings in literature that the 
diffusivity of deionized water through the resin decreases with increasing clay content. ${ }^{(4,5)}$ As can be seen from Table 10 , there is a $32 \%$ decrease in the diffusion coefficient with addition of just $2 \%$ of nanoclay. The time taken for the composites to reach the ultimate weight gain increases as the clay content increases, and is around 10 days for composites with no clay, 15 days for composites with $1 \%$ clay and 21 days for composites with $2 \%$ clay.

An experiment was conducted to verify whether the nanoclay reacts with the alkaline solution. The clay was first heated in a muffle furnace at $750^{\circ} \mathrm{C}$ till all the organic matter (quaternary amine) was burnt. It was found that the clay had a weight loss of $38 \%$ upon ignition. One gram of this ignited clay was dispersed well in $100 \mathrm{ml}$ of the alkaline solution. Also, one gram of the original nanoclay was also dispersed in $100 \mathrm{ml}$ of the alkaline solution. After ten days, both solutions were filtered and the solid was washed with distilled water. The filter papers containing the solids were then dried under infrared light. The weight of the solids was determined by subtracting the weight of the filter paper from the total weight. It was found that there was a $7 \%$ decrease in the weight of the burnt clay and an $8.5 \%$ decrease in the weight of the original clay. From this we were able to infer that both the quaternary amine and the silica framework of the nanoclay are attacked by the alkaline solution.

4.3.2 Dissolution of glass fiber: Figure 9 shows the dissolution of glass fibers in the alkaline solution. The weight loss of the glass fiber mat was measured in 1-week intervals. From Figure 9, we observe that there is almost a 9\% decrease in the weight of glass fibers in just 11 weeks. It appears that the degradation of glass fibers takes place by 
two distinct mechanisms, faster rate in the early stages up to 5 weeks followed by a slower rate thereafter. The faster rate could include the dissolution of the silane coated on the fiber surface while the slower rate could just be the dissolution of the bare fiber. To verify this, the silane coating on the glass fiber was removed by burning off the organic matter in a muffle furnace at $750^{\circ} \mathrm{C}$ for an hour. The burnt glass fiber was then kept immersed in $100 \mathrm{ml}$ of alkaline solution for a week. The weight loss of the original fiber and burnt fiber were $0.53 \%$ and $0.15 \%$, respectively after one week of exposure to alkaline solution. Hence we can infer that the silane coated fiber is attacked at a faster rate than the bare glass fiber. 


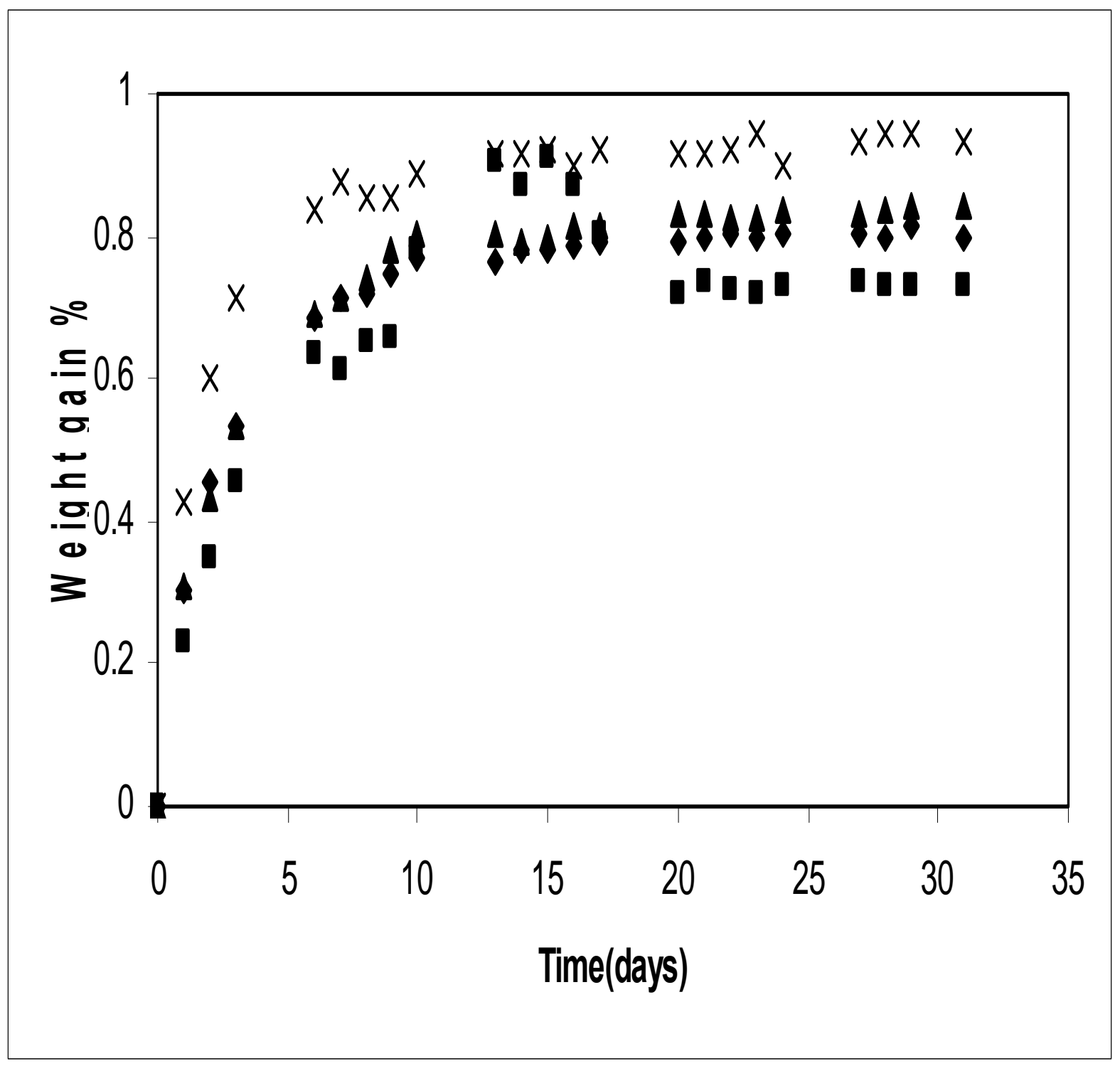

Figure 3. Weight gain \% versus time for neat resin samples 


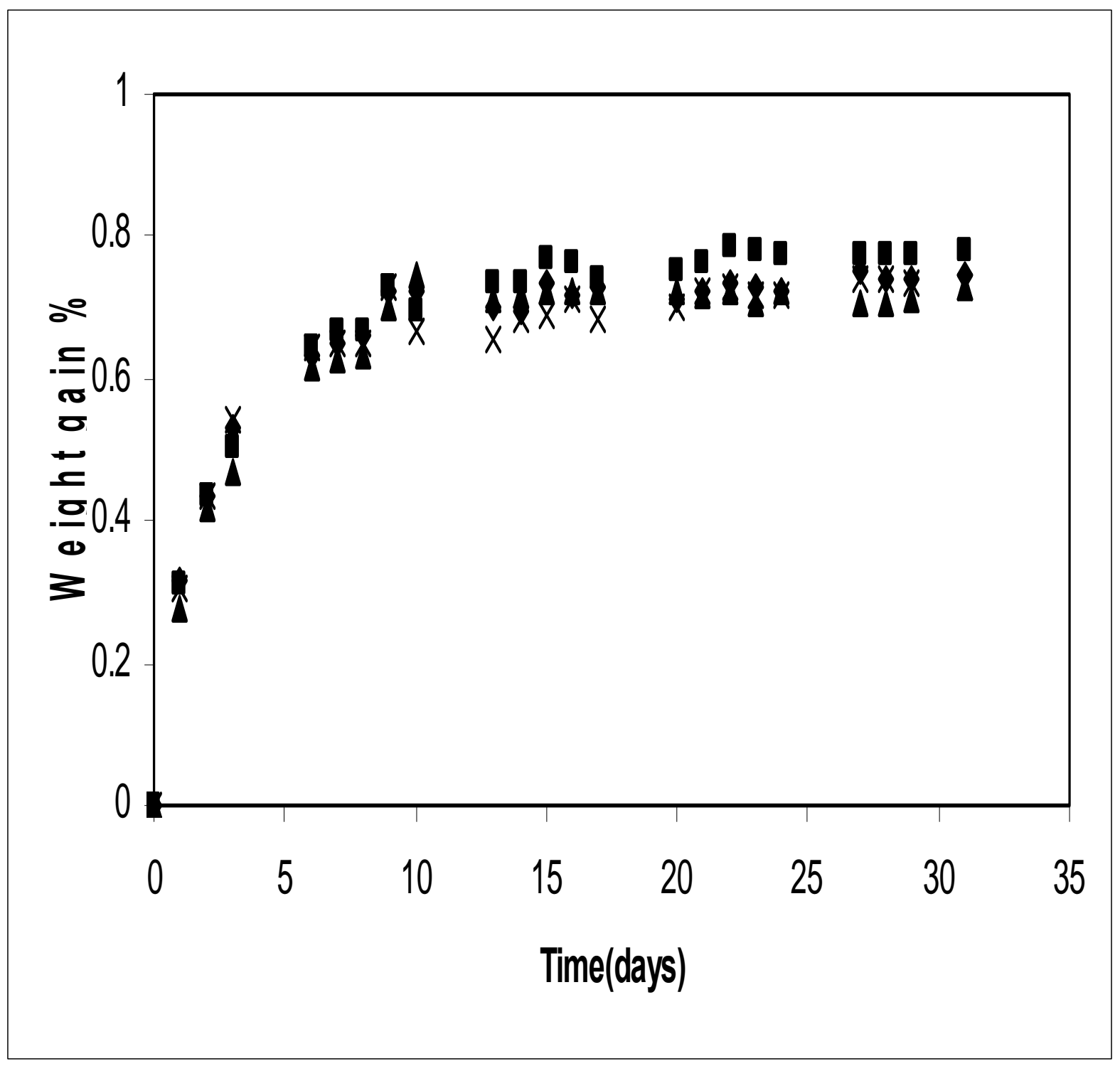

Figure 4 . Weight gain $\%$ versus time for vinyl ester samples with $1 \%$ clay. 


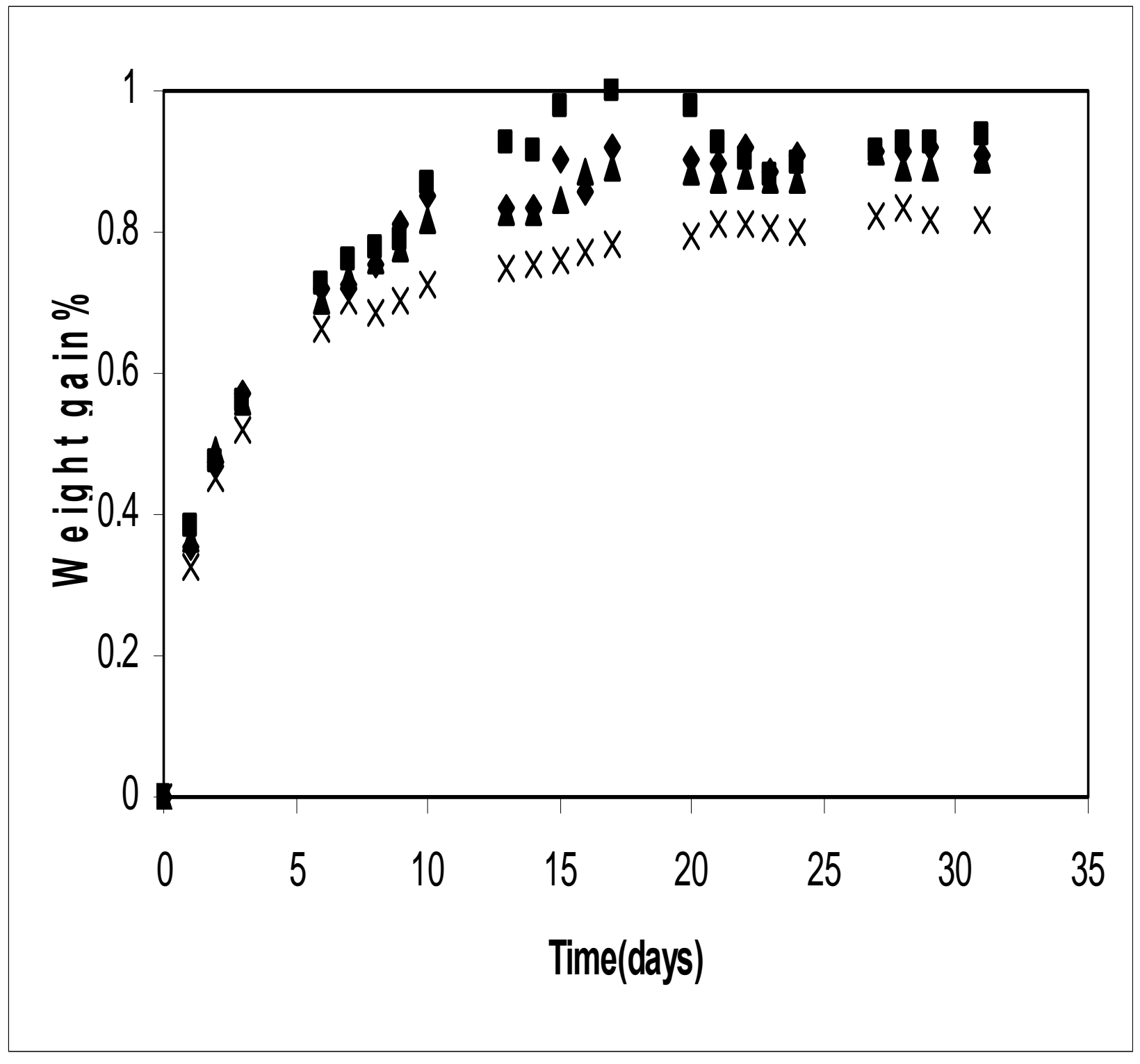

Figure 5 . Weight gain $\%$ versus time for vinyl ester samples with $2 \%$ clay. 


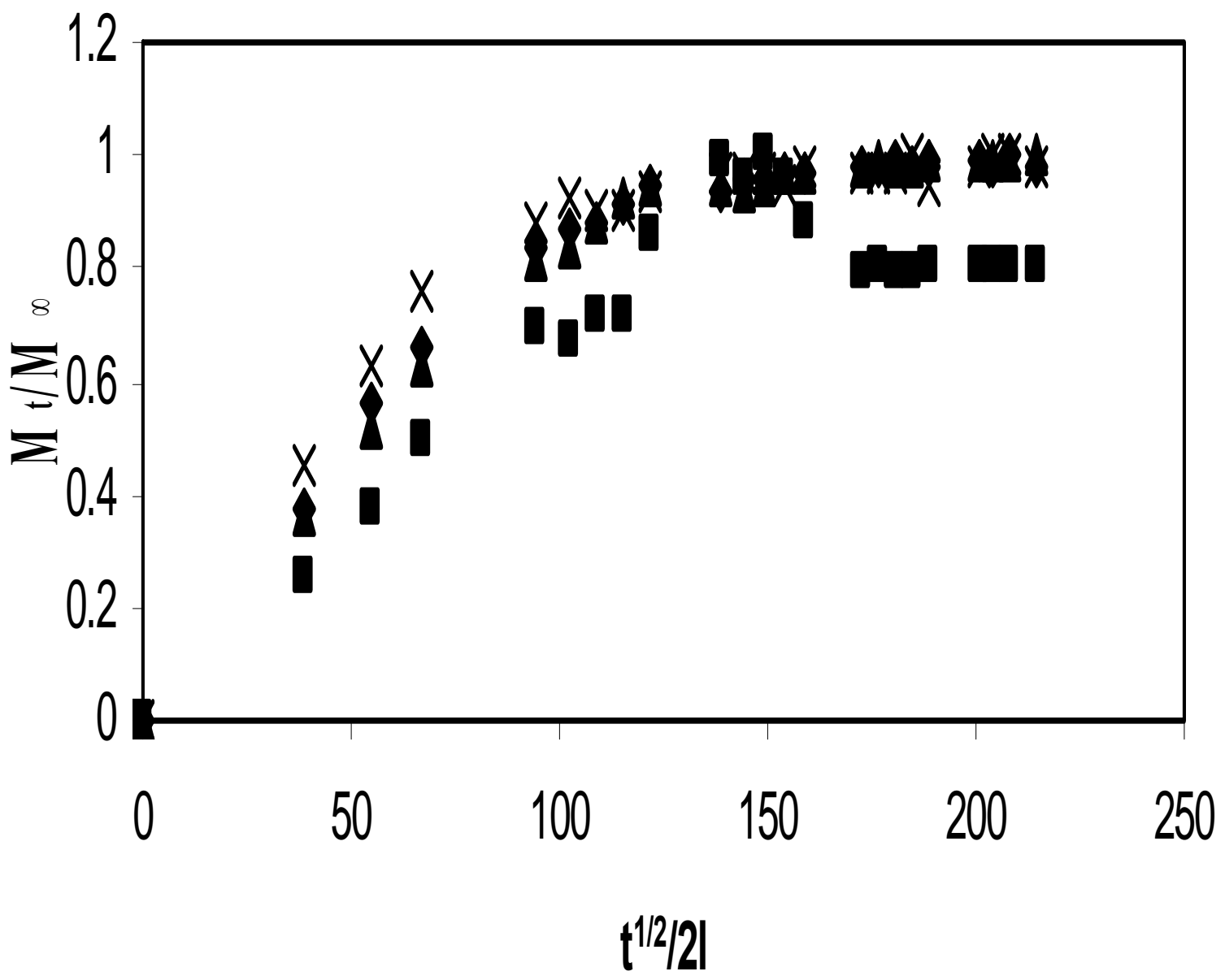

Figure $6 . M_{t} / M_{\infty}$ versus $t^{1 / 2} / 21$ for neat resin samples 


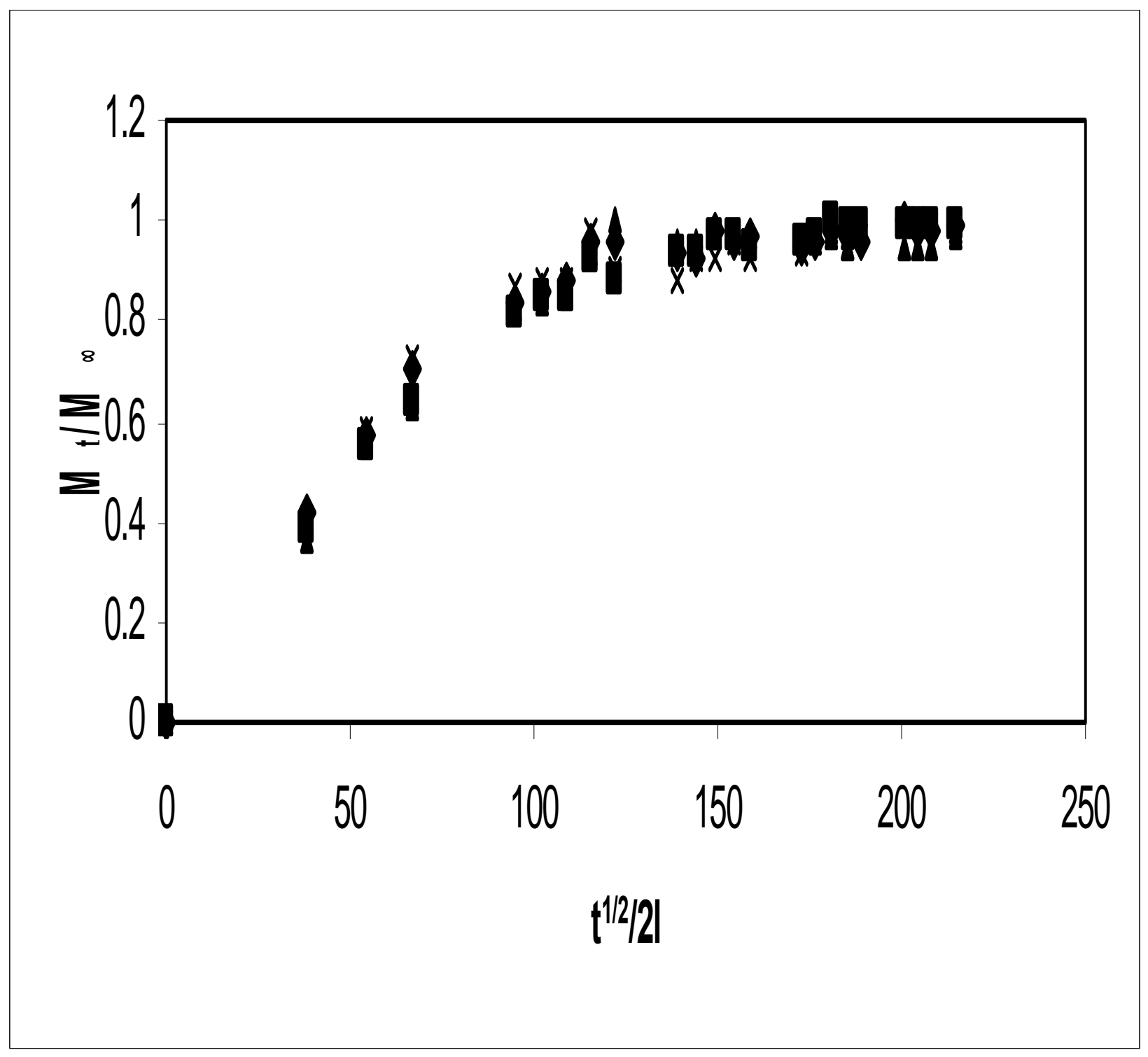

Figure 7. $M_{t} / M_{\infty}$ versus $t^{1 / 2} / 21$ for vinyl ester samples with $1 \%$ nanoclay 


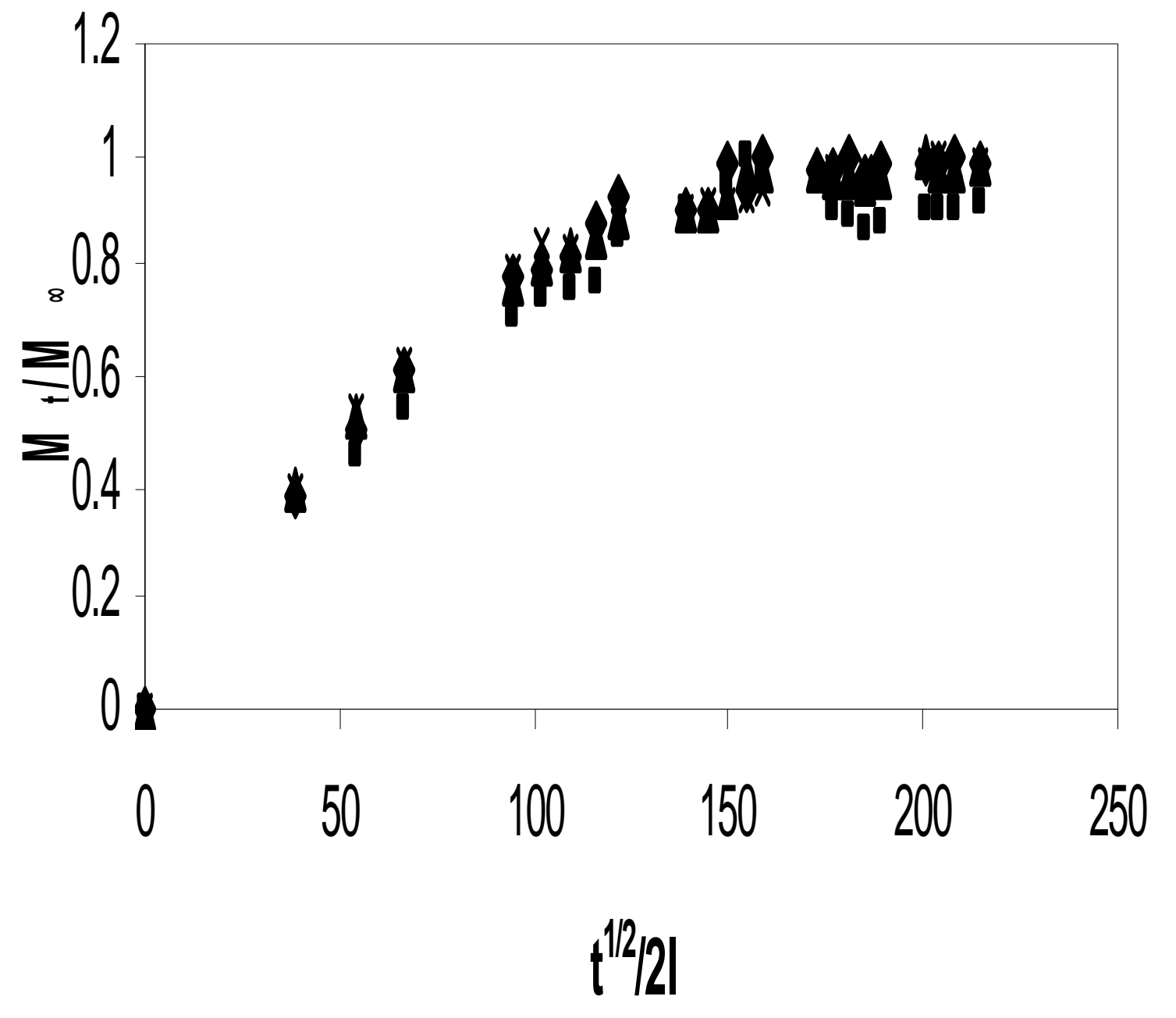

Figure $8 . \mathrm{M}_{\mathrm{t}} / \mathrm{M}_{\infty}$ versus $\mathrm{t}^{1 / 2} / 21$ for vinyl ester samples with $2 \%$ nanoclay 


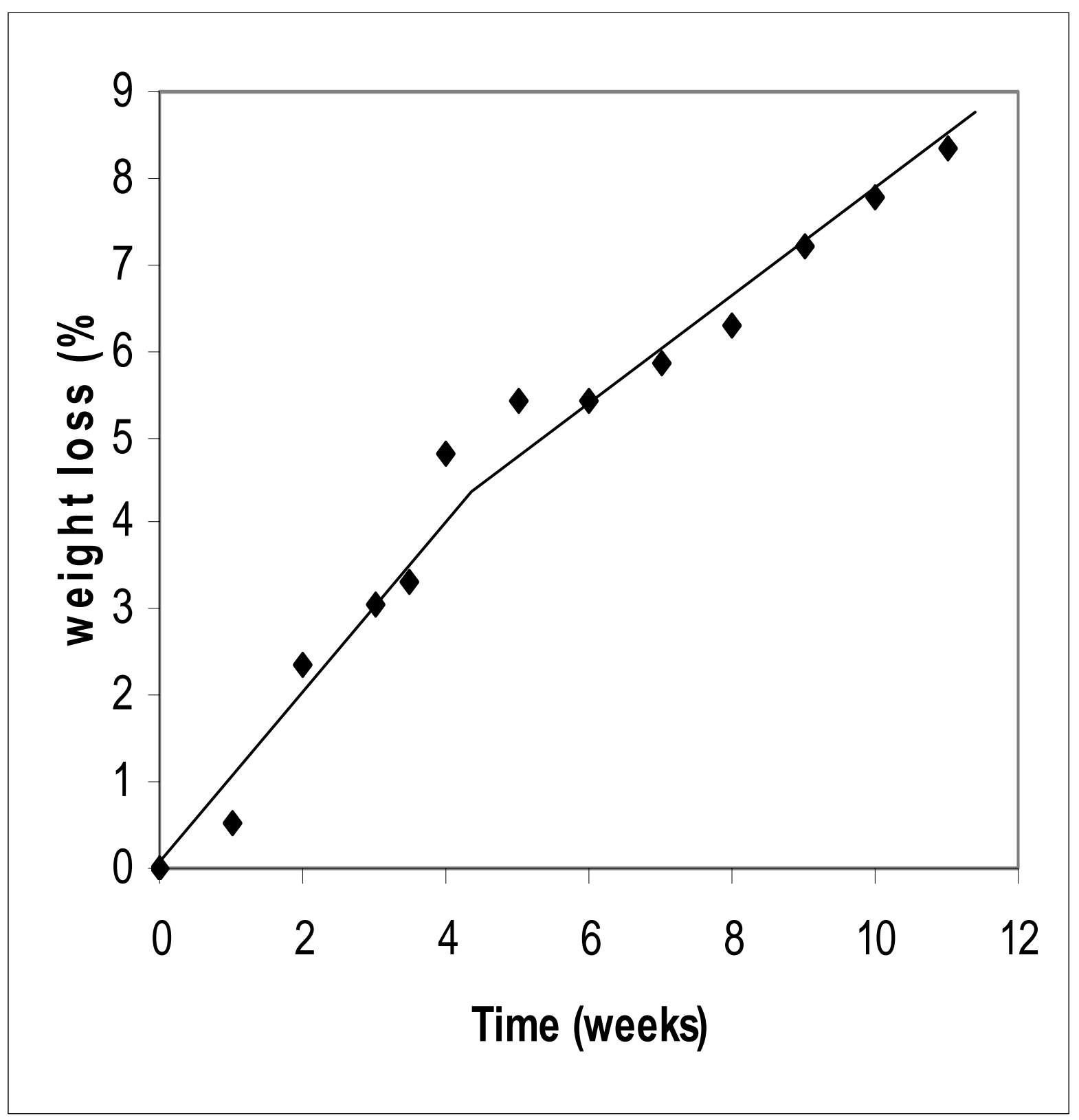

Figure 9. Dissolution of glass fiber mat in alkaline solution of $\mathrm{pH} 13.2$ at room temperature 


\subsubsection{Sorption experiments on GFRPs:}

The weight gain characteristics of GFRP composites with and without clay are shown in Figures 10,11 and 12. Each curve consists of three distinct regions. Weight is gained in the early region; it is lost in the middle region; and levels off in the final region. This can be explained by sorption rate of alkaline solution, the dissolution rate of glass fiber and the desorption rate of the dissolution reaction products. The sorption rate may be larger than the desorption rate in the early region while the opposite holds true for the middle region and the sorption and desorption rates will be equal in the final region.

Each curve shows a peak in a period of 10-15 days. This peak seems to occur because of the dissolution of the glass fiber in the alkaline solution. This becomes evident when we compare Figures 10 through 12 with Figures 3 through 5 which are for the cases without glass fiber. The magnitude of the peak decreases as the clay content increases. The reason for this is not clear at this moment.

The sorption curves demonstrate that the weight decreases with time after the peak. This decrease in weight is undoubtedly due to the faster desorption of the reaction product than the sorption of alkaline solution into the sample, as mentioned previously. The decrease in weight is more pronounced in the samples containing clay than in the samples without clay. The decrease evaluated over the peak height is around $30 \%$ for samples without clay, $72 \%$ for samples with $1 \%$ clay and $76 \%$ for samples with $2 \%$ clay.

Data given in Figures 10, 11 and 12 are plotted in the form of $M t / M_{\infty}$ vs $t^{1 / 2} / 2 l$ and shown in Figures 13, 14 and 15, respectively. For these calculations, the peak weight gain was used to determine $\mathrm{M}_{\infty}$. From the initial slopes of these curves, the diffusion coefficients were calculated according to the method discussed before and the values are 
given in Table 11. One can see from Table 11 that the diffusion coefficient decreases with increasing clay content. There is a decrease of almost $40 \%$ in the diffusivity of GFRP composites with $2 \%$ clay. This is attributed to the barrier effect that the addition of nanoclay brings about in the composites. Accordingly, the diffusing species has to travel a more tortuous path and hence takes a longer time to diffuse through the composite.

Table 11: Diffusion coefficients of GFRP composites with Different Clay Loadings (Values in parentheses are standard deviations.)

\begin{tabular}{|c|c|c|}
\hline$\%$ clay & $\begin{array}{c}\text { Peak Moisture } \\
\text { Content }(\%)\end{array}$ & $\begin{array}{c}\text { Average D }(\mathrm{x} \mathrm{10} \\
\left.\mathrm{cm}^{2} / \mathrm{s}\right)\end{array}$ \\
\hline $0 \%$ & $0.62(0.02)$ & $5.36(0.49)$ \\
\hline $1 \%$ & $0.43(0.06)$ & $4.04(0.16)$ \\
\hline $2 \%$ & $0.31(0.06)$ & $3.24(0.08)$ \\
\hline
\end{tabular}

As in the vinyl ester-nanoclay composites, the GFRP composites without clay seem to reach the peak faster than the GFRP composites with clay. They reach it in 12 days while the $1 \%$ and $2 \%$ nanocomposites take 16 and 21 days, respectively. This result is undoubtedly due to the diffusion retardation in the presence of clay content in the composite samples.

If we take into account, the reaction of the glass fiber and subsequent desorption of the reaction products, $\mathrm{M}_{\infty}$ will not be the peak value. It will be higher than the peak value. Assuming that the ultimate moisture content of the polymer samples without glass fiber from Table 10 as the $\mathrm{M}_{\infty}$ values, and modifying the curves accordingly, we find that the same trend as observed in Table 11. The diffusivity values are slightly lesser than those calculated in Table 11, but the addition of clay reduces the diffusivity and hence protects the fibers. 


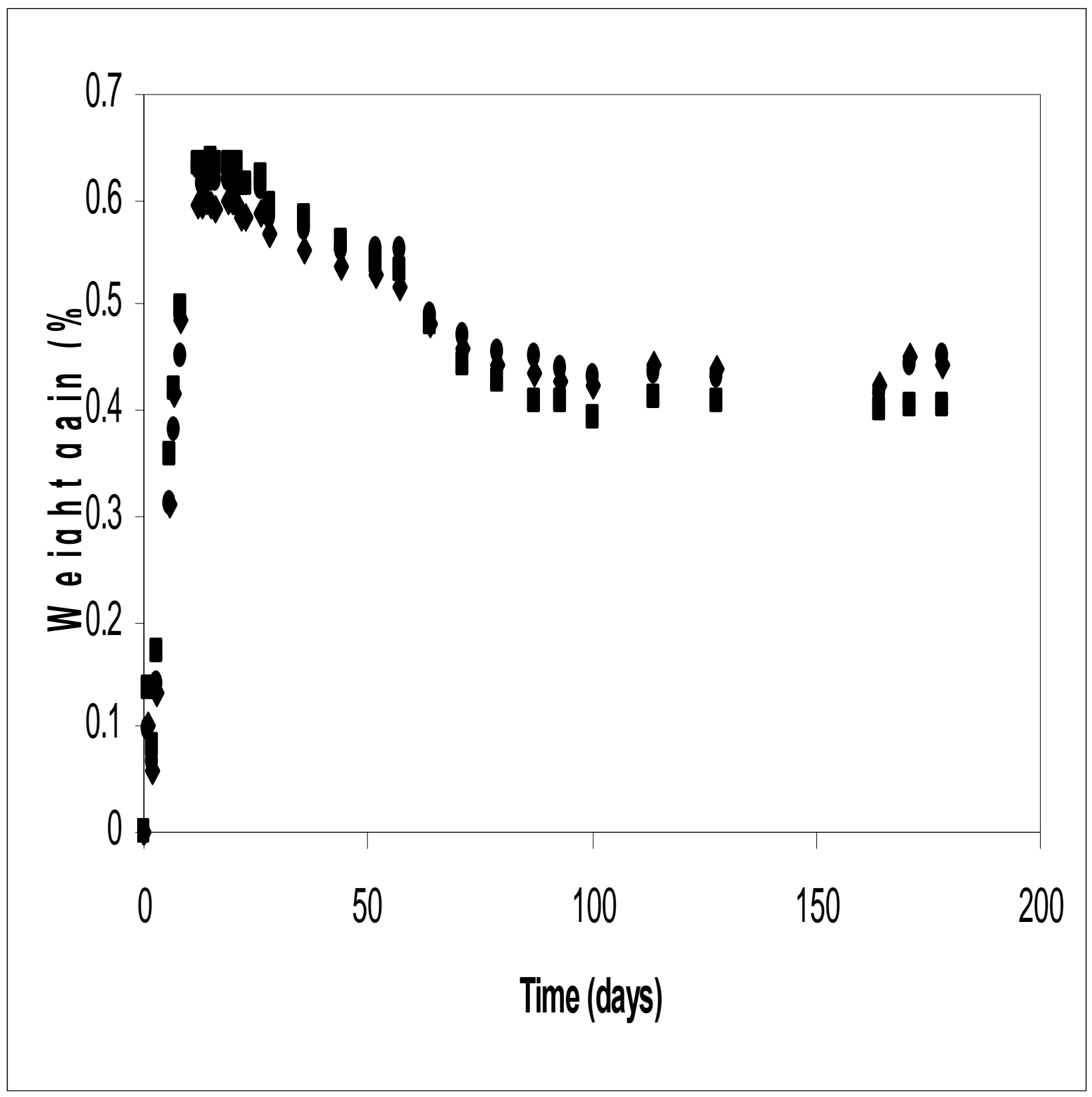

Figure 10 . Weight gain \% versus time for GFRP composites with no clay 


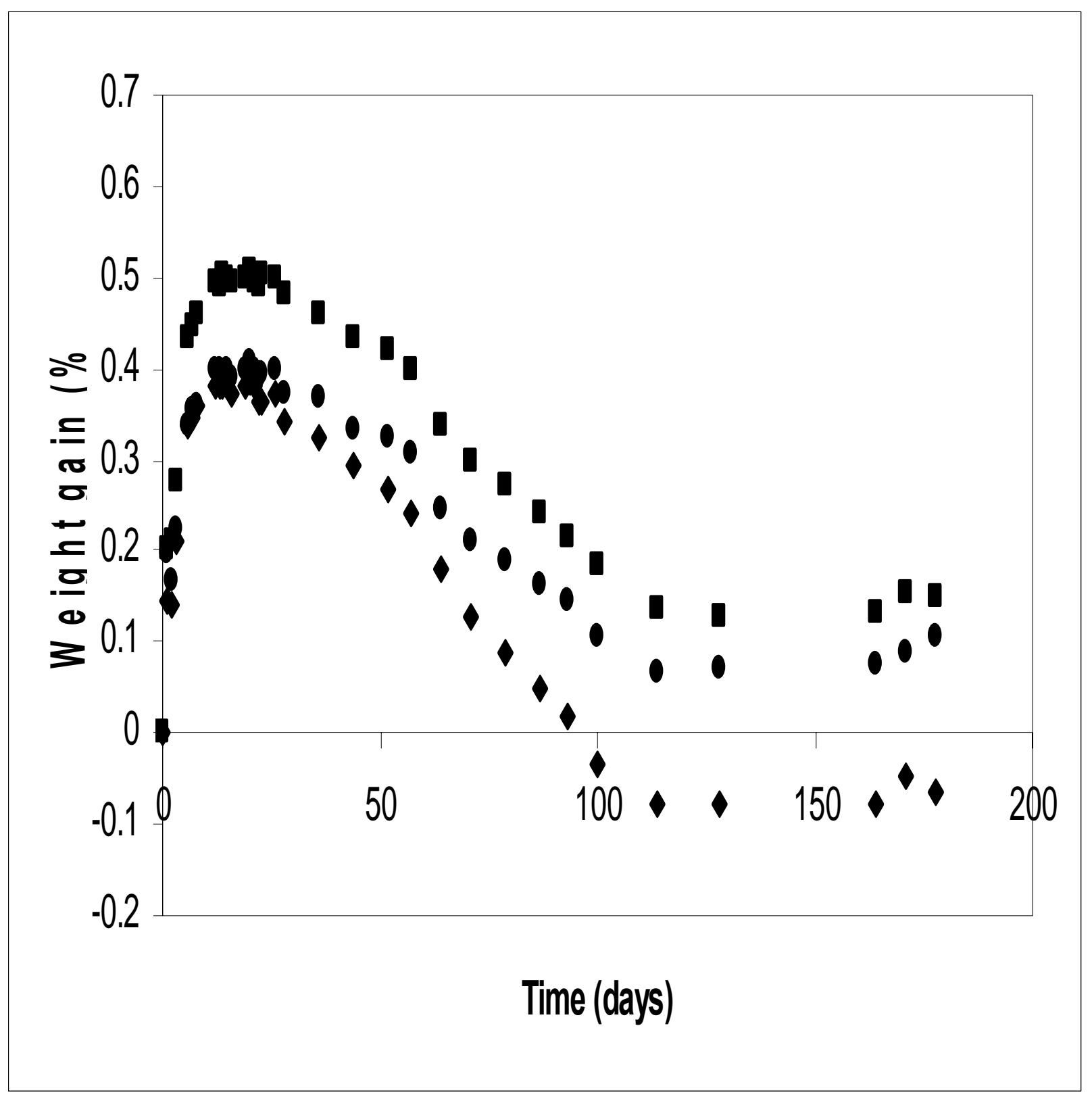

Figure 11. Weight gain \% versus time for GFRP composites with 1\% clay 


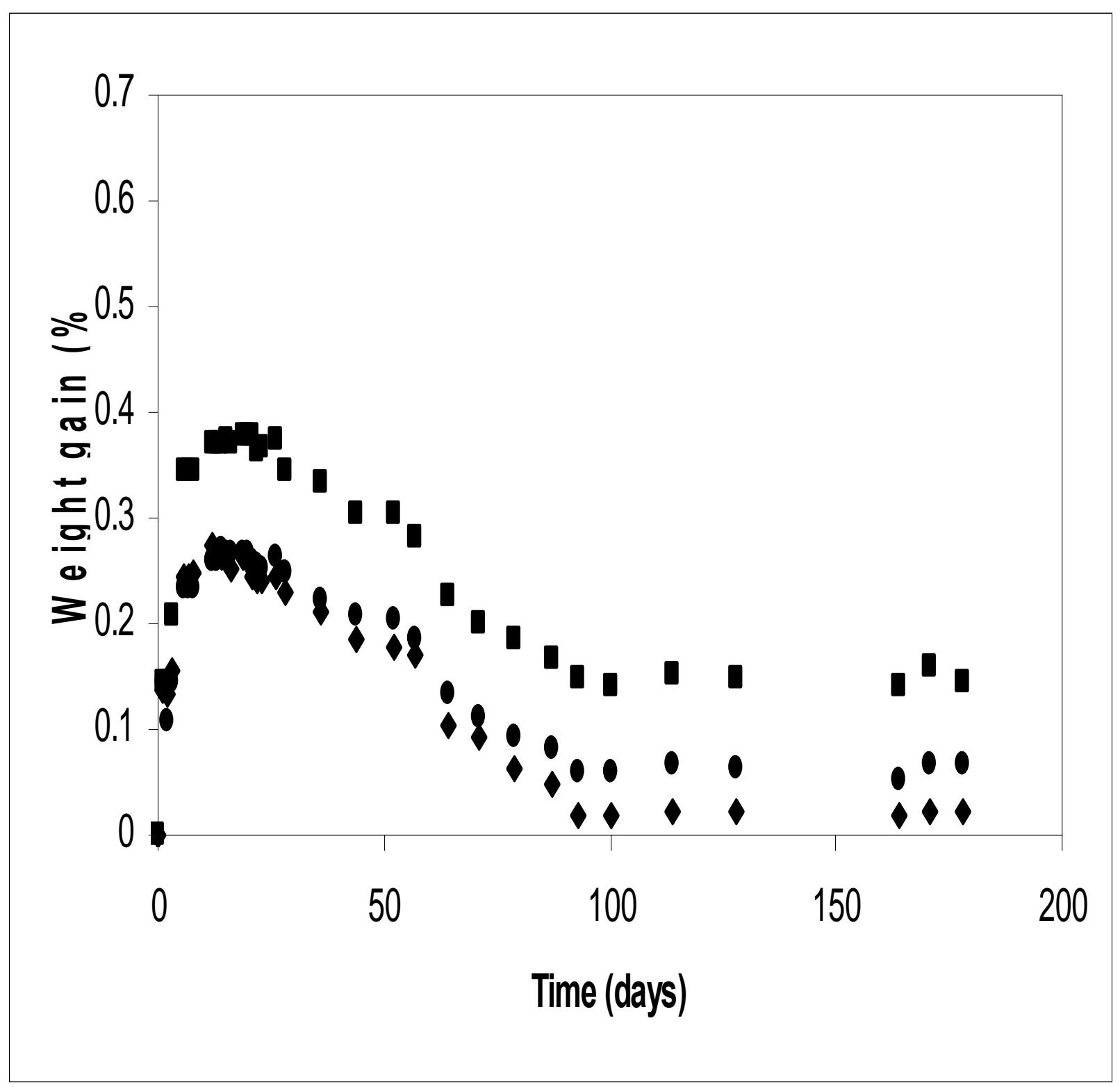

Figure 12 . Weight gain \% versus time for GFRP composites with $2 \%$ clay 


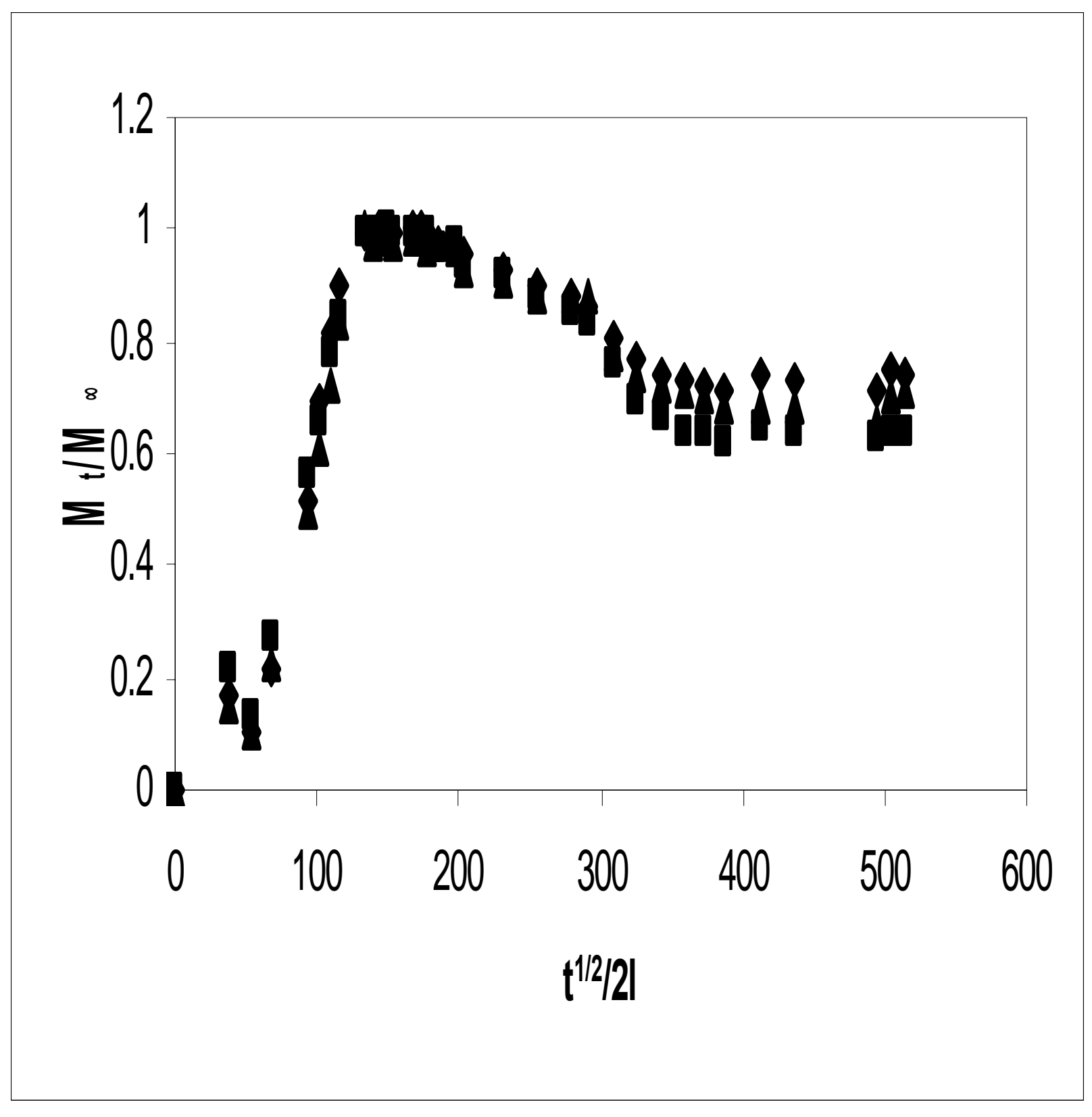

Figure 13. $M_{t} / M_{\infty}$ versus $t^{1 / 2} / 21$ for GFRP samples with no nanoclay 


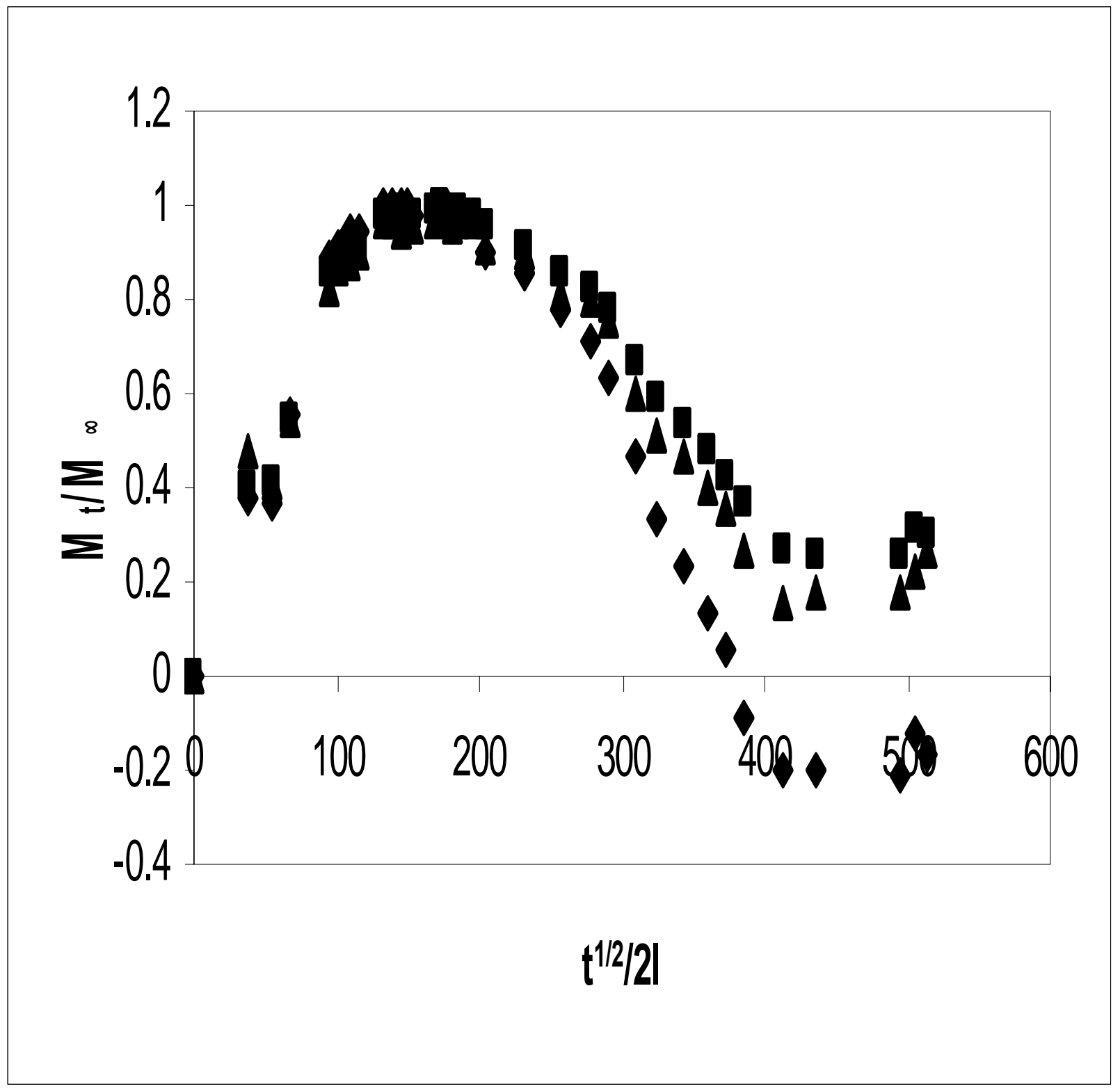

Figure 14. $M_{t} / M_{\infty}$ versus $t^{1 / 2} / 21$ for GFRP samples with $1 \%$ nanoclay 


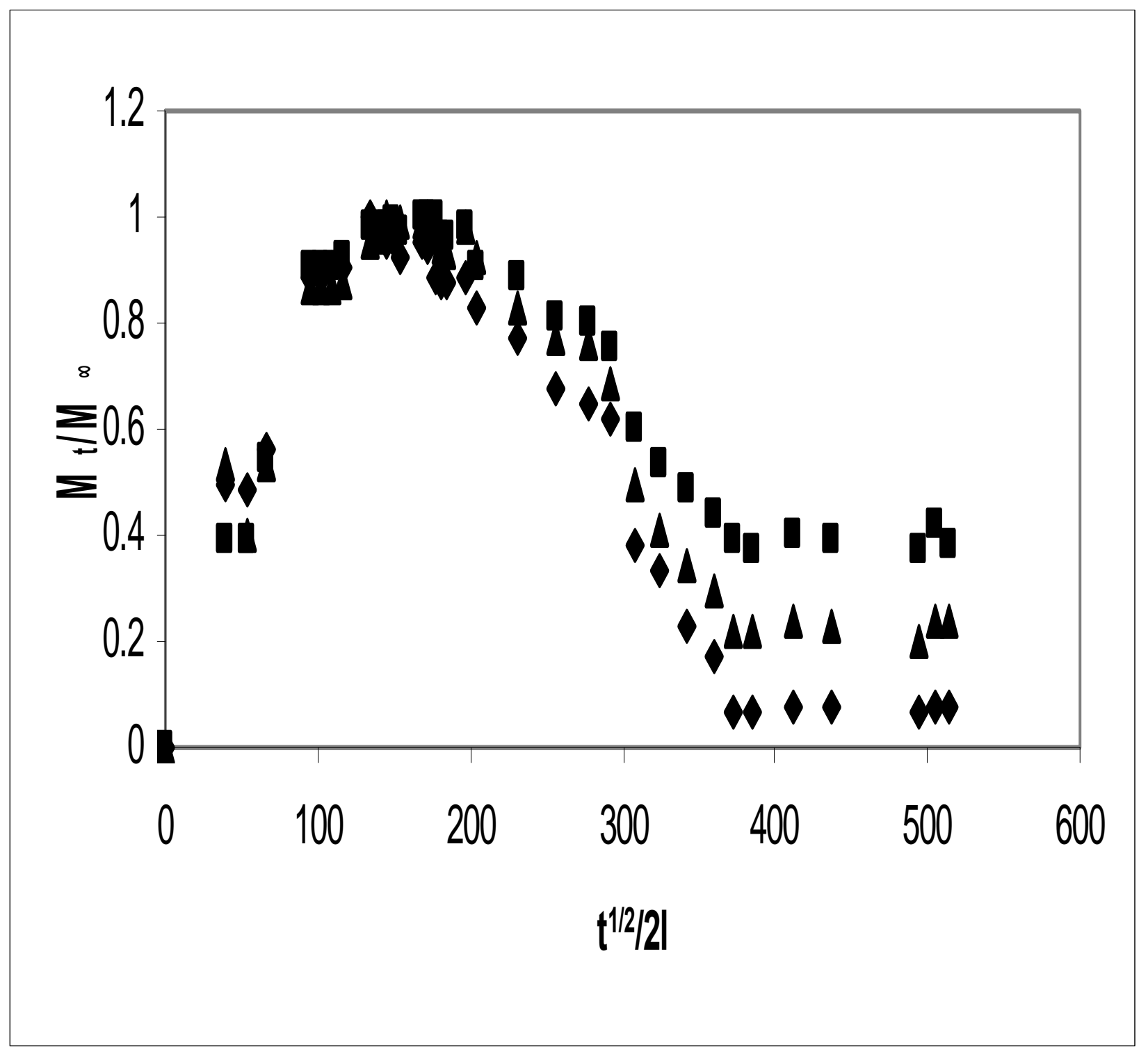

Figure $15 . M_{t} / M_{\infty}$ versus $t^{1 / 2} / 21$ for GFRP samples with $2 \%$ nanoclay 


\subsubsection{GFRP aging without any sustained load:}

The aging effect of GFRP composites in alkaline environment without sustained load was determined by measuring the residual tensile strength of the aged GFRP composites. Tables 12,13 and 14 show the residual tensile strength of GFRP composites with no clay, 1 and $2 \%$ clay, respectively. Table 15 compares the average tensile strengths of these aged GFRP composites with the original tensile strength which are given in Tables 7, 8 and 9. It can be seen that there is little or no difference between the two. In fact, the GFRP composites seem to have gained a slight increase (up to 1.9\%) in the tensile strength through aging for six months. This may be due to the effect of moisture which reduces the glass transition temperature of the GFRP composites and also the effect of additional cross-linking during the period of 6 months which leads to further curing. It is obvious that this effect was not offset by aging with alkaline solution.

Table 12. Residual Tensile Strength of GFRP composites with No Clay aged in Alkaline solution

\begin{tabular}{|c|c|}
\hline Sample & $\begin{array}{c}\text { Residual Tensile } \\
\text { Strength (MPa) }\end{array}$ \\
\hline N2Q-1 & 207.65 \\
\hline N2Q-2 & 210.74 \\
\hline N2Q-3 & 214.05 \\
\hline N2Q-4 & 210.24 \\
\hline N2U-1 & 190.13 \\
\hline N2U-2 & 225.09 \\
\hline N2U-3 & 201.92 \\
\hline N2U-4 & 201.52 \\
\hline N2V-1 & 211.83 \\
\hline N2V-2 & 203.68 \\
\hline N2V-3 & 209.39 \\
\hline N2V-4 & 191.52 \\
\hline Average & $\mathbf{2 0 6 . 4 8}$ \\
\hline STD & $\mathbf{9 . 6 2}$ \\
\hline
\end{tabular}


Table 13. Residual Tensile Strength of GFRP composites with $1 \%$ Clay aged in Alkaline Solution

\begin{tabular}{|c|c|}
\hline Sample & $\begin{array}{c}\text { Residual Tensile } \\
\text { Strength } \mathbf{( M P a )}\end{array}$ \\
\hline N2CAA-1 & 217.43 \\
\hline N2CAA-2 & 240.40 \\
\hline N2CAA-3 & 229.92 \\
\hline N2CAA-4 & 218.83 \\
\hline N2CAF-1 & 195.72 \\
\hline N2CAF-2 & 204.16 \\
\hline N2CAF-3 & 206.15 \\
\hline N2CAF-4 & 190.95 \\
\hline N2CAG-1 & 231.67 \\
\hline N2CAG-2 & 199.48 \\
\hline N2CAG-3 & 190.57 \\
\hline N2CAG-4 & 209.46 \\
\hline Average & $\mathbf{2 1 1 . 2 3}$ \\
\hline STD & $\mathbf{1 6 . 5 4}$ \\
\hline
\end{tabular}

Table 14. Residual Tensile Strength of GFRP composites with $2 \%$ Clay aged in Alkaline Solution

\begin{tabular}{|c|c|}
\hline Sample & $\begin{array}{c}\text { Residual Tensile } \\
\text { Strength (MPa) }\end{array}$ \\
\hline N2CAC-1 & 205.44 \\
\hline N2CAC-2 & 206.42 \\
\hline N2CAC-3 & 207.95 \\
\hline N2CAC-4 & 207.48 \\
\hline N2CAD-1 & 221.19 \\
\hline N2CAD-2 & 239.16 \\
\hline N2CAD-3 & 214.41 \\
\hline N2CAD-4 & 209.13 \\
\hline N2CAE-1 & 226.43 \\
\hline N2CAE-2 & 229.32 \\
\hline N2CAE-3 & 232.07 \\
\hline N2CAE-4 & 203.88 \\
\hline Average & $\mathbf{2 1 6 . 9 1}$ \\
\hline STD & $\mathbf{1 2 . 1 9}$ \\
\hline
\end{tabular}


Table 15. Residual Tensile Strengths of GFRP composites aged in Alkaline Solution for 6 months (Values in parentheses are standard deviations.)

\begin{tabular}{|c|c|c|c|}
\hline \% Clay & $\begin{array}{c}\text { Original Tensile } \\
\text { Strength (MPa) }\end{array}$ & $\begin{array}{c}\text { Residual Tensile } \\
\text { Strength (MPa) }\end{array}$ & \% Increase \\
\hline 0 & $205.77(15.41)$ & $206.48(9.62)$ & 0.35 \\
\hline 1 & $207.30(13.71)$ & $211.23(16.54)$ & 1.90 \\
\hline 2 & $215.04(15.76)$ & $216.91(12.19)$ & 0.87 \\
\hline
\end{tabular}

\subsection{GFRP Aging Under Sustained Load}

The aging of GFRP composites by sustained load in alkaline solution was determined by measuring the residual tensile strengths of the aged GFRP composites for 6 months. The load applied was $1335 \mathrm{~N}$ or $18.75 \%$ of the ultimate tensile strength. The samples were dismantled from the frames, the alkaline solution was poured out of the reservoir and the PVC pipe removed from the rubber cap. Then they were tested for residual tensile strength. During the 6 months, none of the samples failed. Tables 16, 17 and 18 give the residual tensile strengths of the aged GFRP composites with no clay, 1 and $2 \%$ clay, respectively. Table 19 summarizes the average percentage reduction in tensile strength of the GFRP composites with various clay contents.

One can see from Table 19 that the reduction in tensile strength increases with increasing clay content. Since the glass fiber is the main contributor to the strength of the composite, such large reductions in strength suggest that the glass fiber has been degraded more with added clay content. This degradation is caused by faster attack on the glass fiber by the alkaline solution in the presence of clay. 
Table 16. Residual Tensile Strength of GFRP composites with 0\% clay under Sustained Load in Alkaline Solution

\begin{tabular}{|c|c|}
\hline Sample & $\begin{array}{c}\text { Residual Tensile } \\
\text { Strength (MPa) }\end{array}$ \\
\hline N2I-1 & 165.43 \\
\hline N2I-4 & 189.11 \\
\hline N2K-1 & 205.65 \\
\hline N2P-2 & 190.21 \\
\hline N2P-3 & 196.09 \\
\hline N2S-2 & 155.38 \\
\hline N2S-5 & 194.10 \\
\hline N2T-1 & 208.63 \\
\hline N2T-2 & 220.68 \\
\hline N2T-4 & 164.52 \\
\hline N2T-5 & 195.78 \\
\hline Average & $\mathbf{1 8 9 . 6 0}$ \\
\hline STD & $\mathbf{1 9 . 2 4}$ \\
\hline
\end{tabular}

Table 17. Residual Tensile Strength of GFRP composites with 1\% clay under Sustained Load in Alkaline Solution

\begin{tabular}{|c|c|}
\hline Sample & $\begin{array}{c}\text { Residual Tensile } \\
\text { Strength (MPa) }\end{array}$ \\
\hline N2CX-1 & 190.64 \\
\hline N2CX-2 & 188.01 \\
\hline N2CX-3 & 186.53 \\
\hline N2CX-5 & 193.34 \\
\hline N2CY-1 & 179.84 \\
\hline N2CY-2 & 197.69 \\
\hline N2CY-4 & 165.41 \\
\hline N2CZ-1 & 138.62 \\
\hline N2CZ-4 & 187.79 \\
\hline N2CZ-5 & 194.49 \\
\hline Average & $\mathbf{1 8 2 . 2 4}$ \\
\hline STD & $\mathbf{1 7 . 8 2}$ \\
\hline
\end{tabular}


Table 18. Residual Tensile Strength of GFRP composites with 2\% clay under Sustained Load in Alkaline Solution

\begin{tabular}{|c|c|}
\hline Sample & $\begin{array}{c}\text { Residual Tensile } \\
\text { Strength }(\mathrm{MPa})\end{array}$ \\
\hline N2CAB-1 & 223.38 \\
\hline N2CAB-2 & 161.90 \\
\hline N2CAB-3 & 175.84 \\
\hline N2CAB-4 & 193.39 \\
\hline N2CAB-5 & 153.67 \\
\hline N2CAC-5 & 216.84 \\
\hline N2CR-4 & 145.05 \\
\hline N2CS-1 & 181.89 \\
\hline N2CS-2 & 144.50 \\
\hline N2CS-4 & 165.81 \\
\hline Average & $\mathbf{1 7 6 . 2 3}$ \\
\hline STD & $\mathbf{1 7 . 8 9}$ \\
\hline
\end{tabular}

Table 19: Reduction in Tensile Strength of GFRP composites under Sustained Load in Alkaline Solution (values in parentheses are standard deviations)

\begin{tabular}{|c|c|c||c|}
\hline \% Clay & $\begin{array}{c}\text { Original Tensile } \\
\text { Strength (MPa) }\end{array}$ & $\begin{array}{c}\text { Residual Tensile } \\
\text { Strength (MPa) }\end{array}$ & $\begin{array}{c}\text { \% Reduction in } \\
\text { Strength }\end{array}$ \\
\hline \hline 0 & $205.77(15.41)$ & $189.6(19.24)$ & 7.51 \\
\hline 1 & $207.30(13.71)$ & $182.24(17.82)$ & 12.39 \\
\hline 2 & $215.04(15.76)$ & $176.23(17.89)$ & 18.03 \\
\hline
\end{tabular}

A previous study had been conducted with GFRP composites in the presence of various solutions of acid, alkali and salt. ${ }^{(3)}$ It was found that the alkaline solution aged the GFRP composites the most in terms of reduction in tensile strength. It was also observed with the help of SEM pictures that microcracks were formed in the polymer matrix of the samples which were aged in alkaline solution and concluded that the degradation was caused by the formation of microcracks.

Table 19 shows that the reduction in tensile strength increases with increasing clay content. There is a $7.5 \%, 12.39 \%$ and $18.03 \%$ reduction in tensile strength with 0 , 
$1 \%$ and $2 \%$ clay samples, respectively with application of sustained load. This phenomenon may be explained not only by the microcrack mechanism but also by the reaction between the clay and the alkaline solution. This reaction might have etched out portions of clay, which under the influence of sustained load, might provide sites for initiation and propagation of more microcracks. This would then lead to easier diffusion paths for the alkaline solution. Hence the glass fibers in the composites with clay are more exposed to the alkaline solution and are degraded more. Another contributing factor to the phenomenon may be that the more the clay content, the more brittle the resin matrix becomes and thus the more susceptible to cracking. This mechanism may be compared to the stress corrosion cracking of metals.

Comparison between Tables 15 and 19 reveals that the GFRP composites which were aged in alkaline solution without sustained load are not subject to reduction in strength while the opposite is true for GFRP composites which were aged with application of sustained load. It is evident that the application of sustained load for a prolonged period of time such as 6 months has a negative effect on the tensile strength. Furthermore, when the GFRP composites contain clay, the effect seems to be much worse.

However, according to the absorption study, the presence of clay can be beneficial to the composite when exposure time is short. The diffusion coefficient is reduced due to the barrier effect that the clay provides to the polymer matrix, protecting the glass fibers. But for a longer exposure period such as six months, this barrier effect is no longer beneficial because the GFRP becomes saturated with the alkaline solution over the total time frame. 


\section{CHAPTER 5}

\section{CONCLUSIONS}

- Addition of nanoclay to the GFRP composites proves to be both beneficial and detrimental to the durability of the composites in terms of tensile strength reduction depending on whether or not sustained load is applied.

- Without application of sustained load, the addition of clay is beneficial to the durability of the GFRP composites for a short exposure time; however, as time of exposure increases this benefit diminishes to give little or no effect.

- The benefit of the addition of clay for the durability of GFRP composites comes from the retardation of the diffusion of the alkaline solution through the matrix. It was found that the diffusivity decreases by around $32 \%$ with addition of $2 \%$ clay to the polymer matrix while it decreases by almost $39 \%$ with addition of $2 \%$ clay to the GFRP composites.

- With the application of sustained load (18.75\% of the ultimate tensile strength), the presence of clay seems to have an adverse effect on the durability of the composite. The reduction in tensile strength increases as the clay content increases. It increases from $7.5 \%$ with no clay to $18 \%$ with $2 \%$ clay. This phenomenon is thought to be due to the formation of microcracks and also due to the reaction between clay and the alkaline solution. 


\section{REFERENCES}

1. Uomoto, T., "Utilization of FRP Reinforcements for Concrete Structures," 1998, ACCM-1.

2. Vijay, P. V., and GangaRao, H. V. S. "Development of Fiber Reinforced Plastics for Highway Applications (Task A-2), Aging Behavior of Concrete Beams Reinforced with GFRP Bars," Final Report, Submitted to West Virginia Department of Transportation, 1999, No: WVDOH RP \# T-699-FRP-1.

3. Kajorncheappunngam, S., Gupta, R.K. and GangaRao, H.V.S., "Effect of Aging Environment on Degradation of Glass-Reinforced Epoxy," ASCE J. Composites for Construction, 2002, vol. 6, pp. 61.

4. Shah, A.P., Gupta, R.K., GangaRao, H.V.S and Powell, C.E. "Moisture Diffusion through Vinyl Ester Nanocomposites made with Montmorillonite Clay," Poly. Eng. Sci., 2002, vol. 42, pp. 1852.

5. Rana, H.T. "Moisture Diffusion through Neat and Glass Fiber Reinforced Vinyl Ester Resin containing Nanoclay," M. S. Thesis, 2003, Dept. of Chemical Engg., West Virginia University, Morgantown, WV.

6. Karbhari, V.M., Murphy, K. and Zhang, S. "Effect of Concrete Based Alkali Solutions on Short Term Durability of E-Glass/Vinylester Composites," J. Composite Materials, 2003, vol. 36, No.17, pp. 2101.

7. Benmokrane, B., Wang, P., Ton-That, T.M., Rahman, H. and Robert, J. "Durability of Glass Fiber Reinforced Polymer Reinforcing Bars in Concrete Environment," J. Composites for Construction, 2002, vol. 6, No. 3, pp. 143-153

8. Katsuki, F. and Uomoto, T. "Prediction of Deterioration of FRP Rods due to Alkali Attack," Non-metallic (FRP) Reinforcement for Concrete Structures, Taerwe, 1995, ed., FRPCS-2, Ghent, Belgium, pp.108-115.

9. Wallenberg, T.F., Watson, J.C. and Li, H. "Glass Fibers," ASM Handbook Volume 21: Composites, 2001.

10. Vijay, P. V., and GangaRao, H. V. S. "Development of Fiber Reinforced Plastics for Highway Applications (Task A-2), Aging Behavior of Concrete Beams Reinforced with GFRP Bars," Final Report, 1999, No: WVDOH RP \# T-699FRP-1, pp. 38-54.

11. Parratt, N.J. Fiber-Reinforced Materials Technology, Van Nostrand Reinhold Company, London, 1972. 
12. Kornmann, X., Synthesis and Characterisation of Thermoset-Clay Nanocomposites, Div. of Polymer Engg., Lulea University of Technology, Sweden, 1999.

13. Vaia, R. and Giannelis, E. "Polymer Nanocomposites: Status and Opportunities," MRS Bulletin, May 2001, pp. 394-401.

14. Xu, W., Bao, S. and He, P. "Intercalation and Exfoliation of Epoxy Resin/Curing Agent/ Montmorillonite Nanocomposites," J. App. Pol. Sci, 2001, Vol. 84, pp. 842-849.

15. Sheldon, R.P. Composite Polymeric Materials, Applied Science Publishers, London and New York, 1982.

16. Crank, J. and Park, G.S. Diffusion in Polymers, Academic Press, London and New York, 1968.

17. Singh, K.S., Singh, P.N. and Rao, R.M.V.G.K. "Hygrothermal Effects on Chopped Fiber/Woven Fabric Reinforced Epoxy Composites. Part A. Moisture Absorption Characteristics," J. Rein. Plas. Comp., 1991, vol. 10, pp. 446-456.

18. Vijay, P. V., and GangaRao, H. V. S. "Accelerated and Natural Weathering of GFRP Bars," Special Publication (SP)-188, 1999, American Concrete Institute, pp. 605-614.

19. Ji, X.L., Jing, J.K., Jiang, $\mathrm{W}$ and Jiang, B.Z. "Tensile Modulus of Polymer Nanocomposites," J. of Pol. Engg. And Sci. 2002, vol.42, No.5, pp. 983-993.

20. Zhong, J., Wen, W.Y.,and Jones, A.A. "Enhancement of Diffusion in a High Permeability Polymer by the Addition of Nanoparticles," Macromolecules, 2003, vol. 36, pp. 6430-6432.

21. ASTM D 2584, "Standard Test method for Ignition Loss of Cured Reinforced Resins."

22. ASTM D 2734, "Standard Test Methods for Void Content of Reinforced Plastics."

23. ASTM D 3039, "Standard Test Method for Tensile Properties of Polymer Matrix Composite Materials."

24. Christensen, B.J., Mason, T.O. and Jennings, H.M. "Influence of Silica Fume on the Early Hydration of Portland Cements using Impedance Spectroscopy," J. of Amer. Cer. Soc., 1992, vol.75, pp. 939.

25. Yeh, Shu-Kai, "Alkaline Durability tests for E-Glass/Vinyl Ester Reinforced Polymer with Nanoclay," M. S. Thesis, Dept. of Chem. Enof Chem. Engg., WVU, 2003. 


\section{APPENDIX 1}

\section{Calculation of void fraction of GFRP composites:}

According to ASTM D2734, the void fraction of a composite sample is given by the equation,

$$
V=100-M_{d}\left(\frac{r}{d_{r}}+\frac{g}{d_{g}}+\frac{c}{d_{c}}\right)
$$

where

$\mathrm{V}=$ void fraction of the GFRP sample, vol\%

$\mathrm{M}_{\mathrm{d}}=$ measured density of the GFRP sample, $\mathrm{g} / \mathrm{cm}^{3}$

$r=$ weight $\%$ of resin in the GFRP sample

$\mathrm{g}=$ weight $\%$ of glass fiber in the GFRP sample

$\mathrm{c}=$ weight $\%$ of nanoclay in the GFRP sample

$\mathrm{d}_{\mathrm{r}}=$ density of the resin $\left(1.14 \mathrm{~g} / \mathrm{cm}^{3}\right)$

$\mathrm{d}_{\mathrm{g}}=$ density of the glass fibers $\left(2.565 \mathrm{~g} / \mathrm{cm}^{3}\right)$

$\mathrm{d}_{\mathrm{c}}=$ density of the nanoclay $\left(1.9 \mathrm{~g} / \mathrm{cm}^{3}\right)$

The weight $\%$ of resin, fiber and clay can be calculated by performing ignition tests. A GFRP composite sample of dimensions $2.54 \mathrm{~cm} \times 2.54 \mathrm{~cm} \times 0.13 \mathrm{~cm}$ is weighed $\left(\mathrm{W}_{\mathrm{S}}\right)$ and then placed in a furnace. It is burnt at $585{ }^{\circ} \mathrm{C}$ and then cooled. The weight of the residue is recorded $\left(\mathrm{W}_{\mathrm{R}}\right)$. Since the clay also loses its organic matter at this temperature, the loss of weight is also noted by burning a known weight of clay in the furnace and recording the weight of the residue. The loss in weight was found to be $36.38 \%$ of the initial clay weight. 
The following calculations are made to calculate the weights of resin (R), clay (C) and fiber $(\mathrm{F})$ in the test sample:

$$
\begin{aligned}
\mathrm{W}_{\mathrm{S}} & =\mathrm{R}+\mathrm{C}+\mathrm{F} \\
& =\mathrm{R}+0.02 * \mathrm{R}+\mathrm{F} \quad \text { (for samples with } 2 \mathrm{wt} \% \text { nanoclay) } \\
& =1.02 * \mathrm{R}+\mathrm{F} \\
\mathrm{W}_{\mathrm{R}} & =\mathrm{C}_{\mathrm{R}}+\mathrm{F} \quad \quad \text { (where } \mathrm{C}_{\mathrm{R}} \text { is the weight of the clay in the residue) } \\
& =0.6362 * \mathrm{C}+\mathrm{F} \quad \\
& =0.6362 * 0.02 * \mathrm{R}+\mathrm{F} \\
& =0.0127 * \mathrm{R}+\mathrm{F}
\end{aligned}
$$

Now,

$$
\begin{aligned}
\mathrm{W}_{\mathrm{S}}-\mathrm{W}_{\mathrm{R}} & =(1.02 * \mathrm{R}+\mathrm{F})-(0.0127 * \mathrm{R}+\mathrm{F}) \\
& =1.0073 * \mathrm{R}
\end{aligned}
$$

Therefore,

$\mathrm{R}=0.9928 *\left(\mathrm{~W}_{\mathrm{S}}-\mathrm{W}_{\mathrm{R}}\right)$

Knowing R, we can get,

$\mathrm{C}_{\mathrm{R}}=0.0127 * \mathrm{R}$

$\mathrm{C}=0.02 * \mathrm{R}$

$\mathrm{F}=\mathrm{W}_{\mathrm{R}}-\mathrm{C}_{\mathrm{R}}$

Hence knowing the weights of resin, clay and fiber, we can determine the respective weight percentages $\mathrm{r}$, $\mathrm{c}$ and $\mathrm{g}$, and hence the void fraction $\mathrm{V}$ can be calculated. The calculations can be repeated for any $\%$ of clay. 